Supplementary Information for:

\title{
Overcoming Strain-Induced Rearrangement Reactions: A Mild Dehydrative Aromatization Protocol for the Synthesis of Highly Distorted para-Phenylenes
}

Nirmal K. Mitra, Rolande Meudom, Hector H. Corzo, John D. Gorden, and Bradley L. Merner * Department of Chemistry and Biochemistry, Auburn University, Auburn, AL, 36849

\section{TABLE OF CONTENTS}

1. Figure SI-1: Structures/compounds not numbered in the manuscript that appear in the SI

2. Scheme SI-1: Proposed intermediate and possible mechanistic pathways for $p$-terphenyl to $m$ terphenyl rearrangement

3. General experimental conditions, procedures, and characterization data

4. ${ }^{1} \mathrm{H}$ and ${ }^{13} \mathrm{C}$ NMR spectra

5. X-ray crystal structure and relevant data for compounds $\mathbf{2 8}$ and $\mathbf{3 4}$

6. DFT cartesian coordinates for $\mathbf{3 1}$ and $\mathbf{3 4}$

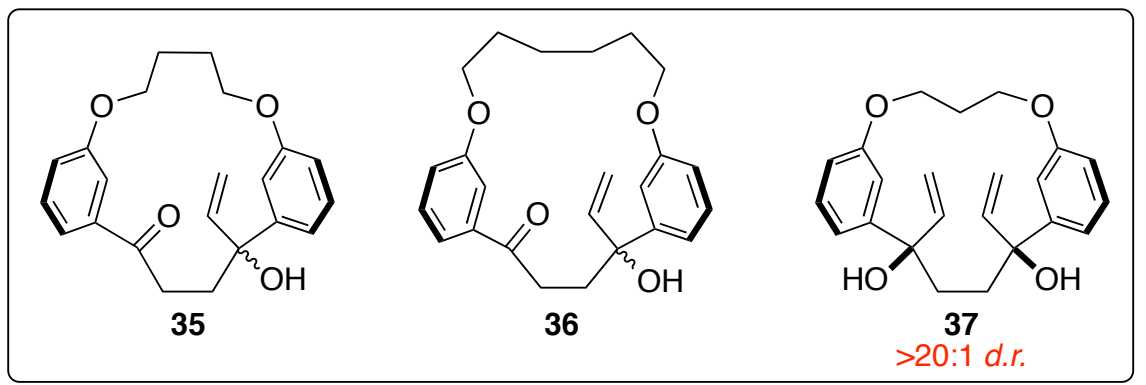

FIGURE SI-1: Structures/compounds not numbered in the manuscript that appear in the SI

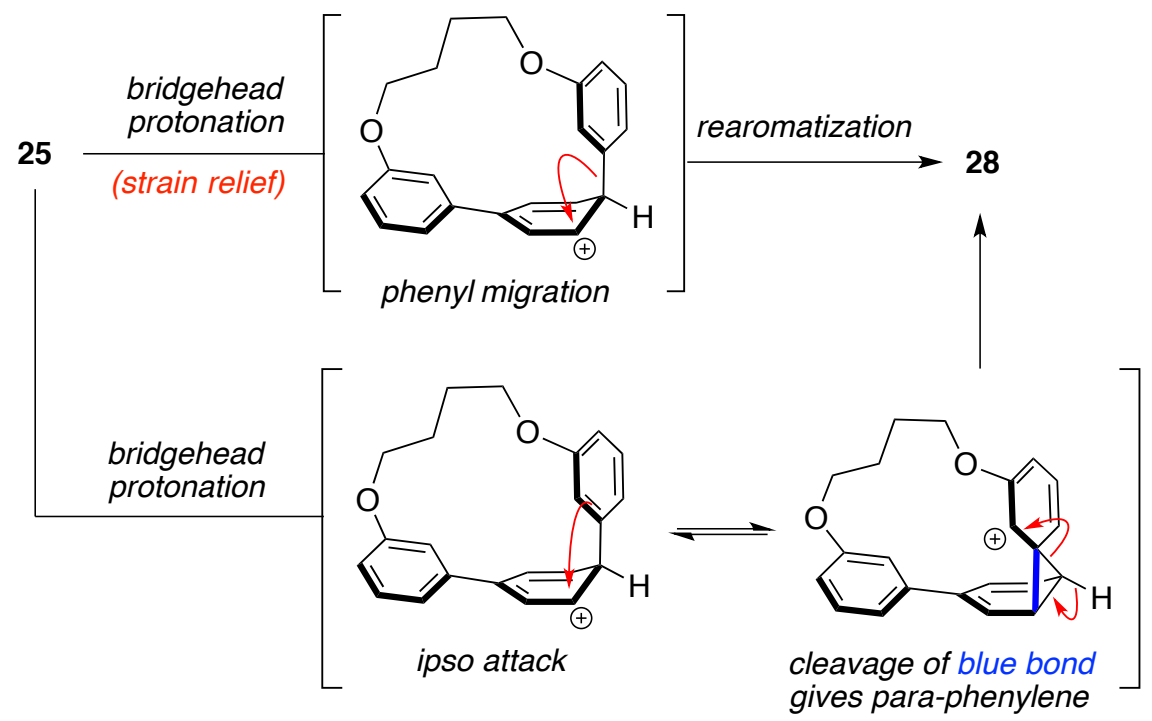

SCHEME SI-1: Proposed intermediate and possible mechanistic pathways for $p$-terphenyl to $m$ terphenyl rearrangement 


\section{General Experimental Conditions}

All reactions were run in flame or oven-dried $\left(120^{\circ} \mathrm{C}\right)$ glassware and cooled under a positive pressure of ultra high pure nitrogen or argon gas. All chemicals were used as received from commercial sources, unless otherwise stated. Anhydrous reaction solvents were purified and dried by passing HPLC grade solvents through activated columns of alumina (Glass Contour SDS). All solvents used for chromatographic separations were HPLC grade (hexanes, ethyl acetate, dichloromethane, chloroform, methanol, and acetone). Chromatographic separations were preformed using flash chromatography, as originally reported by Still and co-workers, on silica gel 60 (particle size 43-60 $\mu \mathrm{m}$ ), and all chromatography conditions have been reported as height $\times$ diameter in centimeters. Reaction progress was monitored by thin layer chromatography (TLC), on glass-backed silica gel plates $(\mathrm{pH}=$ 7.0). TLC plates were visualized using a handheld UV lamp (254 nm) and stained using an aqueous ceric ammonium molybdate (CAM) solution. Plates were dipped, wiped clean, and heated from the back of the plate. ${ }^{1} \mathrm{H}$ and ${ }^{13} \mathrm{C}$ nuclear magnetic resonance (NMR) spectra were recorded at 400 or 600 $\mathrm{MHz}$, calibrated using residual undeuterated solvent as an internal reference $\left(\mathrm{CHCl}_{3}, \delta 7.27\right.$ and 77.2 ppm), reported in parts per million relative to trimethylsilane (TMS, $\delta 0.00 \mathrm{ppm}$ ), and presented as follows: chemical shift $(\delta, \mathrm{ppm})$, multiplicity $(\mathrm{s}=$ singlet, $\mathrm{d}=$ doublet, $\mathrm{dd}=$ doublet of doublets, $\mathrm{ddd}=$ doublet of doublet of doublets, $\mathrm{dt}=$ doublet of triplets, $\mathrm{t}=$ triplet, $\mathrm{m}=$ multiplet, $\mathrm{p}=$ pentet), coupling constants $(J, \mathrm{~Hz})$. High-resolution mass spectrometric (HRMS) data were obtained using a quadrupole time-of-flight (Q-TOF) spectrometer and electrospray ionization (ESI).

\section{Experimental procedures and compound characterization data are presented in numerical order}

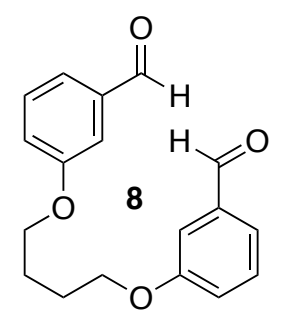

Dialdehyde 8: 1,4-Dibromobutane (5) (3.98 g, $18.4 \mathrm{mmol}$ ) was added to a stirred solution of 3-hydroxybenzaldehyde (5.01 g, $40.9 \mathrm{mmol}), \mathrm{K}_{2} \mathrm{CO}_{3}(5.66 \mathrm{~g}, 41.0 \mathrm{mmol})$ and TBAI $(0.76 \mathrm{~g}, 2.1 \mathrm{mmol})$ in DMF $(40 \mathrm{~mL})$. The reaction was heated at $70{ }^{\circ} \mathrm{C}$ for 48 $\mathrm{h}$, at which point water $(100 \mathrm{~mL})$ and $1 \mathrm{M} \mathrm{HCl}(50 \mathrm{~mL})$ were added sequentially. The resulting mixture was extracted with ethyl acetate $(3 \times 50 \mathrm{~mL})$. The organic extracts were combined and washed with saturated solution of $\mathrm{NaHCO}_{3}(100 \mathrm{~mL})$ and brine $(100 \mathrm{~mL})$, dried over $\mathrm{Na}_{2} \mathrm{SO}_{4}$, filtered and concentrated under reduced pressure. The residue was purified by flash chromatography $(18 \times 5.0 \mathrm{~cm}$; chloroform, $2 \%$ to $5 \%$ acetone/chloroform) to afford 8 as white solid (4.75 g, 87\%): $R_{f}=0.25$ (chloroform); ${ }^{1} \mathrm{H}$ NMR (400 MHz, $\left.\mathrm{CDCl}_{3}\right) \delta 9.97$ (s, 2H), 7.48-7.42 (m, 4H), 7.42-7.37 (m, 


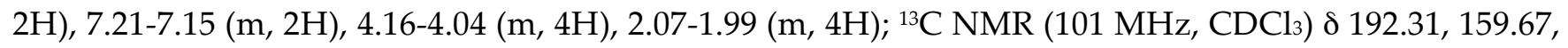
137.97, 130.24, 123.72, 122.09, 112.84, 67.87, 26.04; HRMS (ESI) calculated for $\mathrm{C}_{18} \mathrm{H}_{19} \mathrm{O}_{4}\left([\mathrm{M}+\mathrm{H}]^{+}\right) \mathrm{m} / \mathrm{z}=$ 299.1283, found 299.1290 .

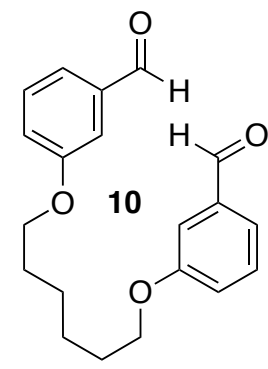

Dialdehyde 10: 1,6-Dibromohexane (7) (1.34 g, $5.49 \mathrm{mmol})$ was added to a stirred solution of 3-hydroxybenzaldehyde (2.03 g, $16.6 \mathrm{mmol})$ and $\mathrm{K}_{2} \mathrm{CO}_{3}(2.78 \mathrm{~g}$, $20.1 \mathrm{mmol})$ in DMF (30 mL). The reaction was heated at $80{ }^{\circ} \mathrm{C}$ for $4 \mathrm{~h}$, at which point water (75 $\mathrm{mL})$ and $1 \mathrm{M} \mathrm{HCl}(30 \mathrm{~mL})$ were added sequentially. The resulting mixture was extracted with ethyl acetate $(3 \times 30 \mathrm{~mL})$. The organic extracts were combined and washed with a saturated solution of $\mathrm{NaHCO}_{3}(40 \mathrm{~mL})$ and brine $(40 \mathrm{~mL})$, dried over $\mathrm{MgSO}_{4}$, filtered and concentrated under reduced pressure. The residue was purified via flash chromatography $(18 \mathrm{~cm}$ $\times 3.8 \mathrm{~cm}$; 9:1 dichloromethane/hexanes, dichloromethane, and 1:9 acetone/dichloromethane) to afford 10 as white solid (1.47 g, 82\%): $\mathrm{R}_{f}=0.35$ (dichloromethane); ${ }^{1} \mathrm{H}$ NMR $\left(600 \mathrm{MHz}, \mathrm{CDCl}_{3}\right) \delta 9.98$ (s, $\left.2 \mathrm{H}\right)$, 7.46-7.43 (m, 4H), $7.39(\mathrm{~s}, 2 \mathrm{H}), 7.19-7.18(\mathrm{~m}, 2 \mathrm{H}), 4.05(\mathrm{t}, J=6.4 \mathrm{~Hz}, 4 \mathrm{H}), 1.88-1.82(\mathrm{~m}, 4 \mathrm{H}), 1.60-1.55(\mathrm{~m}$, $4 \mathrm{H}) ;{ }^{13} \mathrm{C}$ NMR $\left(151 \mathrm{MHz}, \mathrm{CDCl}_{3}\right) \delta$ 192.2, 159.6, 137.8, 130.0, 123.5, 122.0, 112.7, 68.1, 29.1, 25.8; HRMS (ESI) calculated for $\mathrm{C}_{20} \mathrm{H}_{23} \mathrm{O}_{4}\left([\mathrm{M}+\mathrm{H}]^{+}\right) \mathrm{m} / z=327.1596$, found 327.1595.

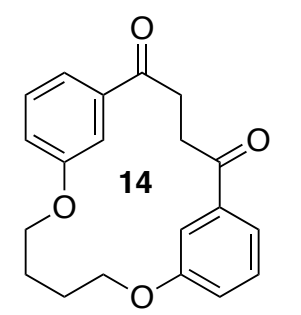

Streamlined synthesis of macrocyclic diketone 14: Vinylmagnesium chloride (1.6 M in THF, $4.6 \mathrm{~mL}, 7.4 \mathrm{mmol})$ was added to a stirred solution of the dialdehyde 8 (1.02 $\mathrm{g}$, $3.42 \mathrm{mmol})$ in THF $(28 \mathrm{~mL})$. After $10 \mathrm{~min}$., the reaction was poured into water (50 $\mathrm{mL})$ and further diluted with $1 \mathrm{M} \mathrm{HCl}(40 \mathrm{~mL})$. The resulting mixture was extracted with dichloromethane $(3 \times 20 \mathrm{~mL})$. The combined organic extracts were washed with a saturated solution $\mathrm{NaHCO}_{3}(30 \mathrm{~mL})$ and water $(30 \mathrm{~mL})$, dried over $\mathrm{Na}_{2} \mathrm{SO}_{4}$, filtered and concentrated under reduced pressure. The pale yellow residue was dissolved in dichloromethane $(224 \mathrm{~mL})$, heated to 40 ${ }^{\circ} \mathrm{C}$, followed by the addition of Hoveyda-Grubbs second-generation catalyst $(0.052 \mathrm{~g}, 0.083 \mathrm{mmol})$. After $1 \mathrm{~h}$, the reaction mixture was concentrated under reduced pressure. The dark brown residue was dissolved in 1:9 methanol/dichloromethane $(34 \mathrm{~mL})$, and sodium borohydride $(0.380 \mathrm{~g}, 10.0 \mathrm{mmol})$ was added. After $3 \mathrm{~h}$, the reaction was poured into water $(50 \mathrm{~mL})$ and further diluted with $1 \mathrm{M} \mathrm{HCl}(20$ $\mathrm{mL})$. The layers were separated and the aqueous phase was extracted with dichloromethane $(2 \times 20$ $\mathrm{mL})$. The combined organic extracts were washed with water $(20 \mathrm{~mL})$, dried over $\mathrm{Na}_{2} \mathrm{SO}_{4}$, filtered and concentrated under reduced pressure. The dark brown residue was dissolved in dichloromethane (34 
$\mathrm{mL})$, followed by the sequential addition of $\mathrm{NaHCO}_{3}(0.846 \mathrm{~g}, 10.1 \mathrm{mmol})$ and Dess-Martin periodinane $(2.91 \mathrm{~g}, 6.86 \mathrm{mmol})$. After $30 \mathrm{~min}$., the reaction was poured into water $(50 \mathrm{~mL})$. The layers were separated and the aqueous phase was extracted with dichloromethane $(2 \times 25 \mathrm{~mL})$. The combined organic extracts were washed with water $(30 \mathrm{~mL})$, dried over $\mathrm{Na}_{2} \mathrm{SO}_{4}$, filtered and concentrated under reduced pressure. The residue was purified by flash chromatography $(15 \times 2.5 \mathrm{~cm}, 3: 7 \mathrm{EtOAc/hexanes)}$ to afford 1,4-diketone 14 as a white solid (0.551 g, 51\% from 8): $R_{f}=0.38$ (3:7 EtOAc/hexanes); ${ }^{1} \mathrm{H}$ NMR $\left(400 \mathrm{MHz} \mathrm{CDCl}_{3}\right) \delta 7.51(\mathrm{dd}, J=7.8,1.3 \mathrm{~Hz}, 2 \mathrm{H}), 7.42-7.35(\mathrm{~m}, 2 \mathrm{H}), 7.25-7.21(\mathrm{~m}, 2 \mathrm{H}), 7.11(\mathrm{ddd}, J=8.2$, 2.5, $1.0 \mathrm{~Hz}, 2 \mathrm{H}), 4.22-4.17(\mathrm{~m}, 4 \mathrm{H}), 3.09$ (s, 4H), 2.00-1.93 (m, 4H); ${ }^{13} \mathrm{C}$ NMR $\left(101 \mathrm{MHz}, \mathrm{CDCl}_{3}\right) \delta$ 199.77, 158.62, 137.57, 130.43, 120.89, 120.05, 115.89, 68.44, 36.22, 25.88; HRMS (ESI) calculated for $\mathrm{C}_{20} \mathrm{H}_{21} \mathrm{O}_{4}$ $\left([\mathrm{M}+\mathrm{H}]^{+}\right) m / z=325.1440$, found 325.1436 .

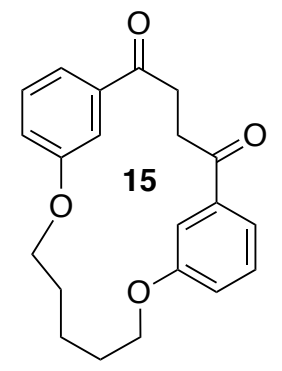

Streamlined synthesis of 1,4-diketones 15: Vinylmagnesium chloride (1.6 M in THF, 5.5 $\mathrm{mL}, 8.8 \mathrm{mmol})$ was added to a stirred solution of $9(1.24 \mathrm{~g}, 3.97 \mathrm{mmol})$ in THF (20 $\mathrm{mL})$. After $10 \mathrm{~min}$. , the reaction was pored into water $(100 \mathrm{~mL})$ and further diluted with $1 \mathrm{M} \mathrm{HCl}(50 \mathrm{~mL})$. The resulting mixture was extracted with dichloromethane (3 $\times 20 \mathrm{~mL}$ ). The combined organic extracts were washed with a saturated solution $\mathrm{NaHCO}_{3}(30 \mathrm{~mL})$ and water $(30 \mathrm{~mL})$, dried over $\mathrm{MgSO}_{4}$, filtered and concentrated under reduced pressure. The pale yellow residue was dissolved in dichloromethane $(220 \mathrm{~mL})$, heated to $40{ }^{\circ} \mathrm{C}$, followed by the addition of Hoveyda-Grubbs second-generation catalyst (0.062 g, $0.099 \mathrm{mmol})$. After 1 $\mathrm{h}$, the reaction mixture was concentrated under reduced pressure. The dark brown residue was dissolved in 1:9 methanol/dichloromethane $(30 \mathrm{~mL})$ and sodium borohydride $(0.619 \mathrm{~g}, 15.9 \mathrm{mmol})$ was added. After $3 \mathrm{~h}$, the reaction was poured into water $(50 \mathrm{~mL})$ and further diluted with $1 \mathrm{M} \mathrm{HCl}(20$ $\mathrm{mL})$. The layers were separated and the aqueous phase was extracted with dichloromethane $(2 \times 20$ $\mathrm{mL})$. The combined organic extracts were washed with water $(20 \mathrm{~mL})$, dried over $\mathrm{MgSO}_{4}$, filtered and concentrated under reduced pressure. The dark brown residue was dissolved in dichloromethane (30 $\mathrm{mL})$, followed by the sequential addition of $\mathrm{NaHCO}_{3}(0.733 \mathrm{~g}, 8.73 \mathrm{mmol})$ and Dess-Martin periodinane (3.37 $\mathrm{g}, 7.89 \mathrm{mmol})$. After $30 \mathrm{~min}$., the reaction was poured into water $(50 \mathrm{~mL})$. The layers were separated and the aqueous phase was extracted with dichloromethane $(2 \times 25 \mathrm{~mL})$. The combined organic extracts were washed with water $(30 \mathrm{~mL})$, dried over $\mathrm{MgSO}_{4}$, filtered and concentrated under reduced pressure. The residue was purified by flash chromatography $(12 \mathrm{~cm} \times 2.5 \mathrm{~cm} ; 3: 7$ EtOAc/hexanes) to afford 1,4-diketone 15 as a white solid $\left(0.885 \mathrm{~g}, 66 \%\right.$ from 9): $R_{f}=0.27(1: 4$ 
EtOAc/hexane); ${ }^{1} \mathrm{H}$ NMR (400 MHz, $\left.\mathrm{CDCl}_{3}\right) \delta 7.49$ (ddd, $\left.J=7.7,1.7,1.0 \mathrm{~Hz}, 2 \mathrm{H}\right), 7.39-7.34(\mathrm{~m}, 2 \mathrm{H}), 7.30$ $(\mathrm{dd}, J=2.5,1.6 \mathrm{~Hz}, 2 \mathrm{H}), 7.07(\mathrm{ddd}, J=8.2,2.5,1.0 \mathrm{~Hz}, 2 \mathrm{H}), 4.11(\mathrm{t}, J=6.2 \mathrm{~Hz}, 4 \mathrm{H}), 3.21(\mathrm{~s}, 4 \mathrm{H}), 1.84(\mathrm{p}, J=$ $6.3 \mathrm{~Hz}, 4 \mathrm{H}), 1.75-1.66(\mathrm{~m}, 2 \mathrm{H}) ;{ }^{13} \mathrm{C}$ NMR (101 MHz, $\left.\mathrm{CDCl}_{3}\right) \delta$ 200.10, 159.05, 137.72, 130.32, 120.70, 119.58, 115.59, 68.01, 36.07, 27.93, 21.98; HRMS (ESI) calculated for $\mathrm{C}_{21} \mathrm{H}_{23} \mathrm{O}_{4}\left([\mathrm{M}+\mathrm{H}]^{+}\right) m / z=339.1596$, found 339.1598 .

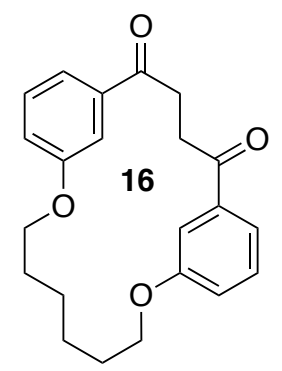

Streamlined synthesis of 1,4-diketones 16: Vinylmagnesium chloride (1.6 M in THF, 4.8 $\mathrm{mL}, 7.7 \mathrm{mmol})$ was added to a stirred solution of $10(1.19 \mathrm{~g}, 3.65 \mathrm{mmol})$ in THF (20 $\mathrm{mL})$. After $10 \mathrm{~min}$., the reaction was poured into water $(100 \mathrm{~mL})$ and further diluted with $1 \mathrm{M} \mathrm{HCl}(50 \mathrm{~mL})$. The resulting mixture was extracted with dichloromethane (3 $\times 20 \mathrm{~mL}$ ). The combined organic extracts were washed with a saturated solution of $\mathrm{NaHCO}_{3}(40 \mathrm{~mL})$ and water $(40 \mathrm{~mL})$, dried over $\mathrm{MgSO}_{4}$, filtered and concentrated under reduced pressure. The pale yellow residue was dissolved in dichloromethane $(240 \mathrm{~mL})$, heated to $40{ }^{\circ} \mathrm{C}$, followed by the addition of Hoveyda-Grubbs second-generation catalyst (0.067 g, $0.107 \mathrm{mmol})$. After 1 $\mathrm{h}$, the reaction mixture was concentrated under reduced pressure. The dark brown residue was dissolved in 1:9 methanol/dichloromethane $(36 \mathrm{~mL})$, and sodium borohydride $(0.652 \mathrm{~g}, 17.2 \mathrm{mmol})$ was added. After $3 \mathrm{~h}$, the reaction was poured into water $(50 \mathrm{~mL})$ and further diluted with $1 \mathrm{M} \mathrm{HCl}(30$ $\mathrm{mL})$. The layers were separated and the aqueous phase was extracted with dichloromethane $(2 \times 20$ $\mathrm{mL})$. The combined organic extracts were washed with water $(20 \mathrm{~mL})$, dried over $\mathrm{MgSO}_{4}$, filtered and concentrated under reduced pressure. The dark brown residue was dissolved in dichlormethane (30 $\mathrm{mL})$, followed by the sequential addition of $\mathrm{NaHCO}_{3}(0.613 \mathrm{~g}, 7.30 \mathrm{mmol})$ and Dess-Martin periodinane (3.09 g, $7.30 \mathrm{mmol})$. After $30 \mathrm{~min}$., the reaction was poured into water $(50 \mathrm{~mL})$. The layers were separated and the aqueous phase was extracted with dichloromethane $(2 \times 25 \mathrm{~mL})$. The combined organic extracts were washed with water $(30 \mathrm{~mL})$, dried over $\mathrm{MgSO}_{4}$, filtered and concentrated under reduced pressure. The residue was purified by flash chromatography $(12 \mathrm{~cm} \times 2.5 \mathrm{~cm}$; $3: 7$ EtOAc/hexanes) to afford 1,4-diketone $\mathbf{1 6}$ as a white solid $\left(0.681 \mathrm{~g}, 53 \%\right.$ from 10): $R_{f}=0.42(2: 3$ EtOAc/hexanes); ${ }^{1} \mathrm{H}$ NMR (400 MHz, $\left.\mathrm{CDCl}_{3}\right){ }^{1} \mathrm{H} \mathrm{NMR}\left(400 \mathrm{MHz}, \mathrm{CDCl}_{3}\right) \delta 7.55$ (ddd, J = 7.7, 1.7, $1.0 \mathrm{~Hz}$, 2H), 7.43-7.35 (m, 4H), $7.09(\mathrm{ddd}, J=8.2,2.5,1.0 \mathrm{~Hz}, 2 \mathrm{H}), 4.08(\mathrm{t}, J=5.8 \mathrm{~Hz}, 4 \mathrm{H}), 3.20(\mathrm{~s}, 4 \mathrm{H}), 1.87-1.77$ (m, 4H), 1.67-1.59 (m, 4H); ${ }^{13} \mathrm{C}$ NMR $\left(101 \mathrm{MHz}, \mathrm{CDCl}_{3}\right) \delta$ 199.67, 159.33, 137.50, 130.36, 120.52, 118.54, 116.23, 67.91, 35.80, 28.24, 25.29; HRMS (ESI) calculated for $\mathrm{C}_{22} \mathrm{H}_{25} \mathrm{O}_{4}\left([\mathrm{M}+\mathrm{H}]^{+}\right) \mathrm{m} / z=353.1753$, found 353.1753. 


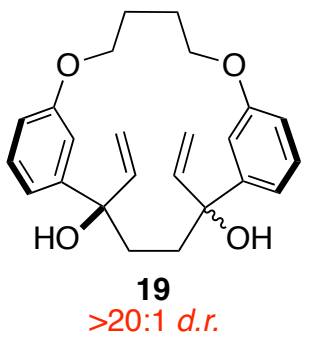

Allylic alcohol 19: 1,4-diketone 12 (0.298 g, $0.925 \mathrm{mmol})$, as a solution in THF (7.5 $\mathrm{mL}$ ) was added to a stirred $65{ }^{\circ} \mathrm{C}$ solution of vinylmagnesium chloride (1.6 $\mathrm{M}$ in THF, $1.8 \mathrm{~mL}, 2.8 \mathrm{mmol})$. After $1 \mathrm{~min}$. , the reaction mixture was poured into water (20 mL) and further diluted with $1 \mathrm{M} \mathrm{HCl}(20 \mathrm{~mL})$. The resulting mixture was extracted with dichloromethane $(3 \times 10 \mathrm{~mL})$. The organic extracts were combined anhydrous $\mathrm{Na}_{2} \mathrm{SO}_{4}$ and concentrated under reduced pressure. The solid residue was purified by flash chromatography $(15 \times 2.5 \mathrm{~cm}, 1: 4 \mathrm{EtOAc} /$ hexanes $)$ to give hydroxyketone $35(0.048 \mathrm{~g}, 15 \%)$ and allylic alcohol $19(0.220 \mathrm{~g}, 63 \% ; 77 \%$ based on recovered 35$)$ predominately as the syn-diastereomer (> 20:1 d.r.).

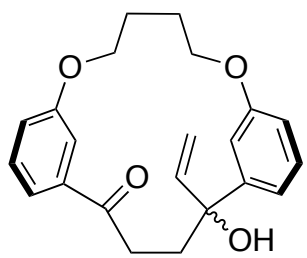

35

Hydroxy ketone 35: $R_{f}=0.35$ (1:4 EtOAc/hexanes); ${ }^{1} \mathrm{H}$ NMR $\left(400 \mathrm{MHz}, \mathrm{CDCl}_{3}\right) \delta 7.53$ $(\mathrm{dt}, J=7.7,1.3 \mathrm{~Hz}, 1 \mathrm{H}), 7.38-7.30(\mathrm{~m}, 2 \mathrm{H}), 7.12(\mathrm{ddd}, J=7.7,1.7,0.9 \mathrm{~Hz}, 1 \mathrm{H}), 7.04$ $(\mathrm{ddd}, J=8.2,2.5,1.0 \mathrm{~Hz}, 1 \mathrm{H}), 6.96-6.93(\mathrm{~m}, 1 \mathrm{H}), 6.92-6.90(\mathrm{~m}, 1 \mathrm{H}), 6.88(\mathrm{dd}, J=2.5$, $1.0 \mathrm{~Hz}, 1 \mathrm{H}), 6.86(\mathrm{dd}, J=2.5,1.0 \mathrm{~Hz}, 1 \mathrm{H}), 5.31(\mathrm{dd}, J=17.3,0.9 \mathrm{~Hz}, 1 \mathrm{H}), 5.15(\mathrm{dd}, J=$ 10.7, $0.8 \mathrm{~Hz}, 1 \mathrm{H}), 4.27-4.17(\mathrm{~m}, 2 \mathrm{H}), 4.18-4.10(\mathrm{~m}, 1 \mathrm{H}), 4.03-3.93(\mathrm{~m}, 1 \mathrm{H}), 2.79-2.56(\mathrm{~m}, 2 \mathrm{H}), 2.44-2.24(\mathrm{~m}$, 2H), 2.13-1.88 (m, 3H); ${ }^{13} \mathrm{C}$ NMR (101 $\left.\mathrm{MHz} \mathrm{CDCl}_{3}\right) \delta 201.84,158.68,158.59,145.39,144.29,137.62$, $129.98,129.74,120.38,119.80,118.30,115.98,113.38,113.34,113.05,77.07,69.16,67.06,39.19,33.75,26.45$, 25.80; HRMS (ESI) calculated for $\mathrm{C}_{22} \mathrm{H}_{23} \mathrm{O}_{3}\left(\left[\mathrm{M}-\left(\mathrm{H}_{2} \mathrm{O}\right)+\mathrm{H}\right]^{+}\right) \mathrm{m} / z=335.1647$, found 335.1647 .

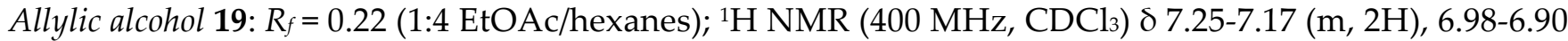
$(\mathrm{m}, 2 \mathrm{H}), 6.80(\mathrm{ddd}, J=8.2,2.5,0.9 \mathrm{~Hz}, 2 \mathrm{H}), 6.72-6.64(\mathrm{~m}, 2 \mathrm{H}), 6.19(\mathrm{dd}, J=17.2,10.7 \mathrm{~Hz}, 2 \mathrm{H}), 5.32(\mathrm{dd}, J=$ 17.3, $1.3 \mathrm{~Hz}, 2 \mathrm{H}), 5.16(\mathrm{dd}, J=10.7,1.3 \mathrm{~Hz}, 2 \mathrm{H}), 4.15-4.00(\mathrm{~m}, 4 \mathrm{H}), 3.08(\mathrm{~s}, 2 \mathrm{H}), 2.04-1.90(\mathrm{~m}, 4 \mathrm{H}), 1.84-$ 1.65 (m, 4H); ${ }^{13} \mathrm{C}$ NMR (101 MHz, $\left.\mathrm{CDCl}_{3}\right) \delta$ 158.71, 146.45, 143.18, 143.16, 129.16, 129.14, 118.47, 113.54, 113.31, 113.29, 112.81, 76.86, 67.50, 36.77, 26.03; HRMS (ESI) calculated for $\mathrm{C}_{24} \mathrm{H}_{25} \mathrm{O}_{2}\left(\left[\mathrm{M}-\left(2 \mathrm{H}_{2} \mathrm{O}\right)+\mathrm{H}\right]^{+}\right) \mathrm{m} / z$ $=345.1855$, found 345.1868 .

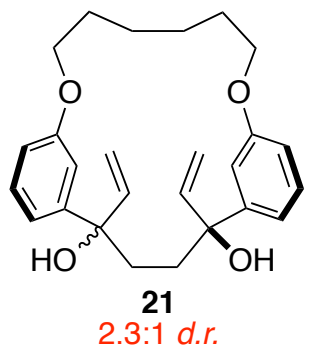

Allylic alcohol 21: 1,4-diketone 12 (0.560 g, $1.59 \mathrm{mmol})$, as a solution in THF (10 $\mathrm{mL})$, was added to a stirred $65{ }^{\circ} \mathrm{C}$ solution vinylmagnesium chloride $(1.6 \mathrm{M}$ in 
THF, $5.2 \mathrm{~mL}, 8.3 \mathrm{mmol})$. After $1 \mathrm{~h}$, the reaction mixture was poured into water $(100 \mathrm{~mL})$ and further diluted with $1 \mathrm{M} \mathrm{HCl}(30 \mathrm{~mL})$. The resulting mixture was extracted with dichloromethane $(3 \times 30 \mathrm{~mL})$. The organic extracts were combined and washed with a saturated solution of $\mathrm{NaHCO}_{3}(30 \mathrm{~mL})$ and brine $(30 \mathrm{~mL})$, dried over anhydrous $\mathrm{MgSO}_{4}$ and concentrated under reduced pressure. The solid residue was purified by flash chromatography $(15 \times 2.5 \mathrm{~cm}, 1: 4 \mathrm{EtOAc/hexanes)}$ to give hydroxyketone $36(0.250 \mathrm{~g}, 41 \%)$ and allylic alcohol $21(0.310 \mathrm{~g}, 47 \% ; 86 \%$ based on recovery of 36) as an inseparable mixture of diastereomers (2.3:1 d.r.):

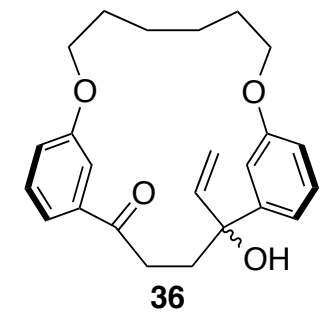

Hydroxy ketone 36: $R_{f}=0.33\left(1: 4 \mathrm{EtOAc/hexanes);}{ }^{1} \mathrm{H} \mathrm{NMR}\left(600 \mathrm{MHz}, \mathrm{CDCl}_{3}\right) \delta\right.$ 7.58-7.52 (m, 1H), 7.37-7.32 (m, 1H), 7.29-7.24 (m, 1H), $7.21(\mathrm{~s}, 1 \mathrm{H}), 7.12(\mathrm{~s}, 1 \mathrm{H}), 7.06$ $(\mathrm{dd}, J=8.1,2.4 \mathrm{~Hz}, 1 \mathrm{H}), 6.93(\mathrm{dd}, J=7.7,1.6 \mathrm{~Hz}, 1 \mathrm{H}), 6.79(\mathrm{dd}, J=8.1,2.6 \mathrm{~Hz}, 1 \mathrm{H})$, $6.26(\mathrm{dd}, J=17.3,10.7 \mathrm{~Hz}, 1 \mathrm{H}), 5.36(\mathrm{~d}, J=17.4 \mathrm{~Hz}, 1 \mathrm{H}), 5.17(\mathrm{~d}, J=10.6 \mathrm{~Hz}, 1 \mathrm{H})$, 4.12-3.96 (m, 4H), $2.95(\mathrm{dt}, J=15.5,7.6 \mathrm{~Hz}, 1 \mathrm{H}), 2.57(\mathrm{dt}, J=15.1,6.6 \mathrm{~Hz}, 1 \mathrm{H}), 2.45$ $(\mathrm{dt}, J=14.8,7.6 \mathrm{~Hz}, 1 \mathrm{H}), 2.33-2.19(\mathrm{~m}, 1 \mathrm{H}), 2.09(\mathrm{~s}, 1 \mathrm{H}), 1.97-1.74(\mathrm{~m}, 4 \mathrm{H}), 1.69-1.56(\mathrm{~m}, 4 \mathrm{H}) ;{ }^{13} \mathrm{C}$ NMR $\left(151 \mathrm{MHz}, \mathrm{CDCl}_{3}\right) \delta$ 201.35, 159.19, 158.89, 145.49, 144.45, 138.18, 129.74, 129.45, 120.02, 118.67, 118.00, 116.16, 112.99, 112.76, 111.58, 76.61, 67.99, 66.45, 37.18, 33.02, 28.09, 27.90, 24.66, 24.33; HRMS (ESI) calculated for $\mathrm{C}_{24} \mathrm{H}_{29} \mathrm{O}_{4}\left([\mathrm{M}+\mathrm{H}]^{+}\right) m / z=381.2066$, found 381.2075.

Allylic alcohol 21 (major isomer): $R_{f}=0.14$ (1:4 EtOAc/hexanes), 0.59 (1:1 EtOAc/hexanes); ${ }^{1} \mathrm{H}$ NMR (600 $\left.\mathrm{MHz}_{2} \mathrm{CDCl}_{3}\right) \delta 7.31(\mathrm{~d}, J=8.0 \mathrm{~Hz}, 2 \mathrm{H}), 7.19(\mathrm{dd}, J=7.7,1.7 \mathrm{~Hz}, 2 \mathrm{H}), 6.80(\mathrm{dd}, J=8.2,2.4 \mathrm{~Hz}, 2 \mathrm{H}), 6.59-$ $6.54(\mathrm{~m}, 2 \mathrm{H}), 6.08(\mathrm{dd}, J=17.3,10.6 \mathrm{~Hz}, 2 \mathrm{H}), 5.18(\mathrm{~d}, J=17.3 \mathrm{~Hz}, 2 \mathrm{H}), 5.01$ (d, J = 10.6 Hz, 2H), 4.11-4.03 $(\mathrm{m}, 2 \mathrm{H}), 3.98-3.94(\mathrm{~m}, 2 \mathrm{H}), 2.51(\mathrm{~s}, 2 \mathrm{H}), 2.02-1.94(\mathrm{~m}, 2 \mathrm{H}), 1.93-1.86(\mathrm{~m}, 2 \mathrm{H}), 1.83-1.76(\mathrm{~m}, 4 \mathrm{H}), 1.73-1.56$ (m, 4H); ${ }^{13} \mathrm{C}$ NMR (151 MHz, $\left.\mathrm{CDCl}_{3}\right) \delta$ 159.2, 146.2, 145.7, 129.4, 117.4, 113.2, 112.3, 111.3, 76.8, 66.8, 35.6, 28.4, 24.7; HRMS (ESI) calculated for $\mathrm{C}_{26} \mathrm{H}_{33} \mathrm{O}_{4}\left([\mathrm{M}+\mathrm{H}]^{+}\right) \mathrm{m} / z=409.2379$, found 409.2380.

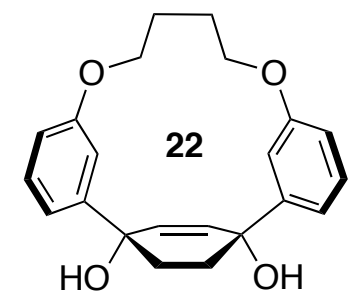

Cyclohex-2-ene-1,4-diol 22: Grubbs' second-generation catalyst (0.023 g, 0.026 mmol) was added to a stirred solution of 19 (>20:1 d.r.; $0.201 \mathrm{~g}, 0.526 \mathrm{mmol})$ in dichloromethane $(35 \mathrm{~mL})$ and the reaction was heated to $40{ }^{\circ} \mathrm{C}$. After $2 \mathrm{~h}$, the solvent was removed under reduced pressure and residue was purified by flash chromatography $(15 \times 2.5 \mathrm{~cm}, 1: 1 \mathrm{EtOAc/hexanes)}$ to give compound 22 as an off-white solid $(0.159 \mathrm{~g}$, 
86\%); $R_{f}=0.27$ (1:1 EtOAc/hexanes); ${ }^{1} \mathrm{H}$ NMR (400 MHz, $\left.\mathrm{CDCl}_{3}\right) \delta$ 7.36-7.27 (m, 4H), 7.05-6.99 (m, 2H), $6.80(\mathrm{ddd}, J=7.7,2.5,1.4 \mathrm{~Hz}, 2 \mathrm{H}), 6.08(\mathrm{~s}, 2 \mathrm{H}), 4.26-4.11(\mathrm{~m}, 2 \mathrm{H}), 4.06-3.93(\mathrm{~m}, 2 \mathrm{H}), 2.17(\mathrm{~s}, 2 \mathrm{H}), 2.14-1.98$ (m, 4H), 1.97-1.78 (m, 4H); ${ }^{13} \mathrm{C}$ NMR (101 MHz, $\left.\mathrm{CDCl}_{3}\right) \delta$ 158.64, 147.77, 134.96, 130.23, 117.59, 114.70, 113.81, 73.25, 69.81, 37.00, 26.98. HRMS (ESI) calculated for $\mathrm{C}_{22} \mathrm{H}_{23} \mathrm{O}_{3}\left(\left[\mathrm{M}-\left(\mathrm{H}_{2} \mathrm{O}\right)+\mathrm{H}\right]^{+}\right) \mathrm{m} / z=335.1647$, found 335.1641.

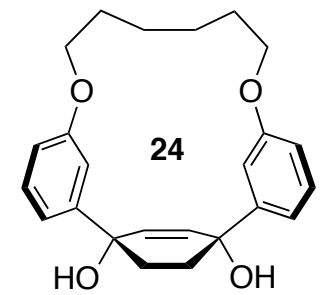

Cyclohex-2-ene-1,4-diol 22: Grubbs' second-generation catalyst (0.020 g, $0.023 \mathrm{mmol})$ was added to a stirred solution of 21 (2.3:1 d.r.; $0.380 \mathrm{~g}, 0.930 \mathrm{mmol})$ in dichloromethane $(23 \mathrm{~mL})$ and the reaction was heated to $40{ }^{\circ} \mathrm{C}$. After $2 \mathrm{~h}$, the solvent was removed under reduced pressure and residue was purified by flash chromatography $(15 \times 2.5 \mathrm{~cm}, 3: 7 \mathrm{EtOAc/hexanes)}$ to give compound 24 as an off-white solid (0.225 g, 59\%, 85\% based on recovered anti-21) and (uncyclized) anti-21 (0.106 g, 92\% recovery).

anti-21: $R_{f}=0.33$ (1:4 EtOAc/hexanes); ${ }^{1} \mathrm{H}$ NMR (600 MHz, $\left.\mathrm{CDCl}_{3}\right) \delta$ 7.30-7.23 (m, 2H), 7.15-7.10 (m, 2H), 6.79-6.73 (m, 2H), 6.58-6.52 (m, 2H), $6.06(\mathrm{dd}, J=17.2,10.6 \mathrm{~Hz}, 2 \mathrm{H}), 5.15(\mathrm{dd}, J=17.2,1.0 \mathrm{~Hz}, 2 \mathrm{H}), 5.00$ $(\mathrm{dd}, J=10.6,1.0 \mathrm{~Hz}, 2 \mathrm{H}), 4.03(\mathrm{dt}, J=9.3,4.8 \mathrm{~Hz}, 2 \mathrm{H}), 3.94(\mathrm{td}, J=9.2,3.9 \mathrm{~Hz}, 2 \mathrm{H}), 2.00(\mathrm{~s}, 2 \mathrm{H}), 1.95-1.88$ $(\mathrm{m}, 2 \mathrm{H}), 1.88-1.80(\mathrm{~m}, 2 \mathrm{H}), 1.79-1.72(\mathrm{~m}, 1 \mathrm{H}), 1.69-1.50(\mathrm{~m}, 6 \mathrm{H}) ;{ }^{13} \mathrm{C} \mathrm{NMR}\left(151 \mathrm{MHz}, \mathrm{CDCl}_{3}\right) \delta 159.15$, 146.18, 145.66, 129.43, 117.42, 113.21, 112.31, 111.30, 76.80, 66.75, 35.64, 28.38, 24.71; HRMS (ESI) calculated for $\mathrm{C}_{26} \mathrm{H}_{33} \mathrm{O}_{4}\left([\mathrm{M}+\mathrm{H}]^{+}\right) \mathrm{m} / z=409.2379$, found 409.2372 .

Cyclohex-2-ene-1,4-diol 22: $R_{f}=0.29$ (1:1 EtOAc/hexanes); ${ }^{1} \mathrm{H}$ NMR $\left(600 \mathrm{MHz}, \mathrm{CDCl}_{3}\right) \delta$ 7.32-7.26 (m, 4H), 6.93-6.88 (m, 2H), 6.80-6.74 (m, 2H), $5.96(\mathrm{~s}, 2 \mathrm{H}), 4.02-3.94(\mathrm{~m}, 4 \mathrm{H}), 2.54(\mathrm{~s}, 2 \mathrm{H}), 2.08-2.03(\mathrm{~m}, 2 \mathrm{H}), 1.86-$ $1.74(\mathrm{~m}, 6 \mathrm{H}), 1.63-1.55(\mathrm{~m}, 4 \mathrm{H}) ;{ }^{13} \mathrm{C}$ NMR $\left(101 \mathrm{MHz}, \mathrm{CDCl}_{3}\right) \delta$ 158.83, 147.84, 134.66, 130.13, 117.49, 113.76, 112.62, 72.98, 67.62, 36.33, 27.78, 24.63; HRMS (ESI) calculated for $\mathrm{C}_{24} \mathrm{H}_{27} \mathrm{O}_{3}\left(\left[\left(\mathrm{M}-\mathrm{H}_{2} \mathrm{O}\right)+\mathrm{H}\right]^{+}\right) \mathrm{m} / z=$ 363.1960, found 363.1968.

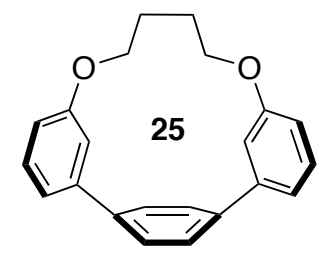

1,6-dioxa[6](3,3')-p-Terphenylenophane (25): $p$-Toluene sulfonic acid monohydrate $(0.130 \mathrm{~g}, 0.684 \mathrm{mmol})$ was added to a stirred solution of $22(0.040 \mathrm{~g}, 0.11 \mathrm{mmol})$ in toluene $(6 \mathrm{~mL})$. The reaction was heated at $50{ }^{\circ} \mathrm{C}$ for $10 \mathrm{~h}$ and then to $60{ }^{\circ} \mathrm{C}$ for $5 \mathrm{~h}$. After $15 \mathrm{~h}$, a saturated solution of $\mathrm{NaHCO}_{3}(20 \mathrm{~mL})$ was added. The layers were separated and the aqueous phase was extracted with dichloromethane $(2 \times 10 \mathrm{~mL})$. The organic extracts 
were combined and washed with brine $(20 \mathrm{~mL})$, dried over anhydrous $\mathrm{Na}_{2} \mathrm{SO}_{4}$ and concentrated under reduced pressure. The residue was purified by flash chromatography $(15 \times 1.3 \mathrm{~cm}, 5 \%$ EtOAc/hexanes $)$ to afford 25 as a white solid $(0.015 \mathrm{~g}, 42 \%): R_{f}=0.43$ (5\% EtOAc/hexanes); ${ }^{1} \mathrm{H} \mathrm{NMR}\left(600 \mathrm{MHz}, \mathrm{CDCl}_{3}\right) \delta$ $7.37(\mathrm{~s}, 4 \mathrm{H}), 7.36-7.32(\mathrm{~m}, 2 \mathrm{H}), 7.26-7.24(\mathrm{~m}, 2 \mathrm{H}), 6.78(\mathrm{dd}, J=8.4,2.7 \mathrm{~Hz}, 2 \mathrm{H}), 5.31(\mathrm{~d}, J=2.9 \mathrm{~Hz}, 2 \mathrm{H})$, 3.95-3.89 (s, 4H), 1.46-1.40 (m, 4H); $\left.{ }^{13} \mathrm{C} \mathrm{NMR} \mathrm{(151} \mathrm{MHz,} \mathrm{CDCl}_{3}\right) \delta$ 156.29, 144.82, 144.55, 130.30, 117.70, 115.81, 115.69, 67.29, 22.77; HRMS (EI) calculated for $\mathrm{C}_{22} \mathrm{H}_{21} \mathrm{O}_{2}\left(\mathrm{M}^{+}\right) \mathrm{m} / z=316.1463$, found 316.1437.

Alternate procedure for 25 (Table 1, entry 4): Sodium hydrogen sulfate monohydrate (0.008 g, $0.06 \mathrm{mmol})$ was added to a stirred $130{ }^{\circ} \mathrm{C}$ solution of $22(0.010 \mathrm{~g}, 0.028 \mathrm{mmol})$ and $o$-chloranil $(0.035 \mathrm{~g}, 0.14 \mathrm{mmol})$ in DMSO $(0.75 \mathrm{~mL})$ and xylenes $(2 \mathrm{~mL})$. After $24 \mathrm{~h}$, the reaction mixture was cooled to room temperature and a saturated solution of $\mathrm{NaHCO}_{3}(10 \mathrm{~mL})$ and dichloromethane $(10 \mathrm{~mL})$ were added. The layers were separated and the aqueous phase was extracted with dichloromethane $(2 \times 10 \mathrm{~mL})$. The corganic extracts were combined, filtered through a pad of Celite $(2 \mathrm{~cm})$, and the filtrate was concentrated under reduced pressure. The residue was purified by flash chromatography $(7.5 \times 0.6 \mathrm{~cm}$; $5 \%$ EtOAc/hexanes) to afford the 25 as a white solid $(0.0032 \mathrm{~g}, 36 \%)$. A trace amount of the [6]MTPP isomer was observed in the ${ }^{1} \mathrm{H}$ NMR spectrum of 25.

Alternate procedure for 25 (Table 1, entry 10): Burgess reagent $(0.021 \mathrm{~g}, 0.088 \mathrm{mmol})$ was added to a stirred solution of $22(0.010 \mathrm{~g}, 0.028 \mathrm{mmol})$ in toluene $(2 \mathrm{~mL})$ at $80{ }^{\circ} \mathrm{C}$. After $15 \mathrm{~min}$., the reaction was cooled to room temperature, water $(10 \mathrm{~mL})$ was added, and the resulting mixture was stirred for $5 \mathrm{~min}$. The layers were separated and the mixture was extracted with dichloromethane $(3 \times 5 \mathrm{~mL})$. The organic extracts were combined and washed with brine $(10 \mathrm{~mL})$, dried over anhydrous $\mathrm{MgSO}_{4}$ and concentrated under reduced pressure. The residue was purified by flash chromatography $(12 \times 1.3 \mathrm{~cm}$, 1:1 dichloromethane/hexanes) to afford 25 as a white solid (0.005 g, 56\%).

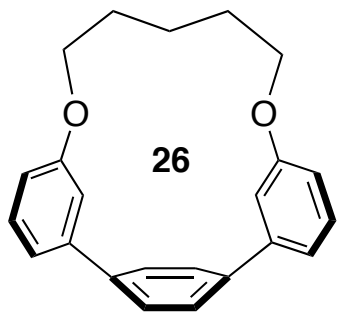

1,7-dioxa[7](3,3')-p-Terphenylenophane (26) (Table 1, entry 11): Burgess reagent $(0.050 \mathrm{~g}, 0.21 \mathrm{mmol})$ was added to a stirred solution of $23(0.026 \mathrm{~g}, 0.071 \mathrm{mmol})$ in toluene $(3 \mathrm{~mL})$ at $80{ }^{\circ} \mathrm{C}$. After $15 \mathrm{~min}$., the reaction was cooled to room temperature, water $(10 \mathrm{~mL})$ was added, and the resulting mixture was stirred for $5 \mathrm{~min}$. The layers were separated and the mixture was extracted with dichloromethane $(3 \times 10 \mathrm{~mL})$. The organic extracts were combined and washed with brine $(10 \mathrm{~mL})$, 
dried over anhydrous $\mathrm{MgSO}_{4}$ and concentrated under reduced pressure. The residue was purified by flash chromatography $(12 \times 1.3 \mathrm{~cm}, 1: 1$ dichloromethane/hexanes) to afford 26 as a white solid $(0.016 \mathrm{~g}$, 68\%): $R_{f}=0.32\left(1: 19 \mathrm{EtOAc/hexanes);}{ }^{1} \mathrm{H}\right.$ NMR $\left(400 \mathrm{MHz}, \mathrm{CDCl}_{3}\right) \delta 7.44(\mathrm{~s}, 4 \mathrm{H}), 7.35$ (dd, J = 8.2, $7.4 \mathrm{~Hz}$, 2H), 7.30-7.24 (m, 2H), $6.78(\mathrm{ddd}, J=8.3,2.8,1.0 \mathrm{~Hz}, 2 \mathrm{H}), 5.81(\mathrm{dd}, J=2.8,1.5 \mathrm{~Hz}, 2 \mathrm{H}), 4.10-4.05(\mathrm{~m}, 4 \mathrm{H})$, 1.51-1.42 (m, 4H), 1.21-1.12 (m, 2H); ${ }^{13} \mathrm{C}$ NMR (101 MHz, $\left.\mathrm{CDCl}_{3}\right)$ ठ 157.2, 144.7, 144.1, 130.6, 129.5, 118.7, $115.9,115.4,68.5,26.8,23.3$; HRMS (EI) calculated for $\mathrm{C}_{23} \mathrm{H}_{22} \mathrm{O}_{2}\left([\mathrm{M}]^{+}\right) \mathrm{m} / z=330.1618$, found, 330.1620 .

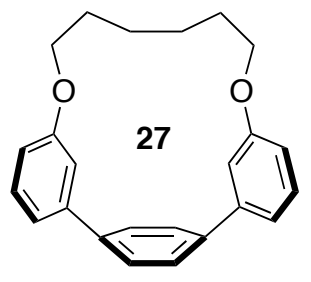

1,8-dioxa[8](3,3")-p-Terphenylenophane (27): p-Toluene sulfonic acid monohydrate $(0.502 \mathrm{~g}, 2.92 \mathrm{mmol})$ was added to a stirred solution of $24(0.184 \mathrm{~g}, 0.484 \mathrm{mmol})$ in toluene $(20 \mathrm{~mL})$ and the reaction was heated to $60{ }^{\circ} \mathrm{C}$. After $2 \mathrm{~h}$, a saturated solution of $\mathrm{NaHCO}_{3}(20 \mathrm{~mL})$ was added to the reaction. The layers were separated and the aqueous phase was extracted with dichloromethane $(3 \times 15 \mathrm{~mL})$. The organic extracts were combined and washed with brine $(30 \mathrm{~mL})$, dried over anhydrous $\mathrm{Na}_{2} \mathrm{SO}_{4}$ and concentrated under reduced pressure. The residue was purified by flash chromatography $(15 \times 1.3 \mathrm{~cm}, 1: 1$ dichloromethane/hexanes) to afford 27 as a white solid $(0.120 \mathrm{~g}, 74 \%): \quad R_{f}=0.41 \quad(1: 1$ dichloromethane/hexanes); ${ }^{1} \mathrm{H}$ NMR $\left(400 \mathrm{MHz}, \mathrm{CDCl}_{3}\right) \delta 7.39(\mathrm{~s}, 4 \mathrm{H}), 7.36$ (dd, J = 8.3, 7.4 Hz, 2H), 7.26$7.20(\mathrm{~m}, 2 \mathrm{H}), 6.84(\mathrm{ddd}, J=8.3,2.7,0.9 \mathrm{~Hz}, 2 \mathrm{H}), 5.92(\mathrm{dd}, J=2.8,1.4 \mathrm{~Hz}, 2 \mathrm{H}), 4.08-3.99(\mathrm{~m}, 4 \mathrm{H}), 1.62-1.50$ (m, 4H), 1.12-1.04 (m, 4H); ${ }^{13} \mathrm{C}$ NMR $\left(151 \mathrm{MHz}, \mathrm{CDCl}_{3}\right) \delta$ 156.86, 144.54, 143.59, 130.21, 128.76, 117.46, 116.63, 115.88, 68.42, 27.81, 27.63; HRMS (EI) calculated for $\mathrm{C}_{24} \mathrm{H}_{24} \mathrm{O}_{2}\left([\mathrm{M}]^{+}\right) \mathrm{m} / z=344.1931$ found 344.1896.

Alternate procedure for 28 (Table 1, entry 13): Burgess reagent $(0.058 \mathrm{~g}, 0.24 \mathrm{mmol})$ was added to a stirred solution of $24(0.021 \mathrm{~g}, 0.082 \mathrm{mmol})$ in toluene $(3 \mathrm{~mL})$ at $80{ }^{\circ} \mathrm{C}$. After $15 \mathrm{~min}$., the reaction was cooled to room temperature, water $(10 \mathrm{~mL})$ was added, and the resulting mixture was stirred for $5 \mathrm{~min}$. The layers were separated and the mixture was extracted with dichloromethane $(3 \times 10 \mathrm{~mL})$. The organic extracts were combined and washed with brine $(10 \mathrm{~mL})$, dried over anhydrous $\mathrm{MgSO}_{4}$ and concentrated under reduced pressure. The residue was purified by flash chromatography $(12 \times 1.3 \mathrm{~cm}$, 1:1 dichloromethane/hexanes) to afford 25 as a white solid $(0.017 \mathrm{~g}, 60 \%)$. 


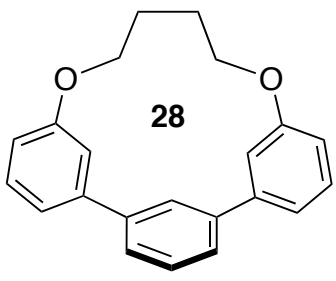

1,6-dioxa[6](3,3")m-Terphenylophane (28): para-Toluensulfonic acid monohydrate $(0.033 \mathrm{~g}, 0.17 \mathrm{mmol})$ was added to a stirred $70{ }^{\circ} \mathrm{C}$ of $25(0.011 \mathrm{~g}, 0.035 \mathrm{mmol})$ in toluene $(2 \mathrm{~mL})$. After $12 \mathrm{~h}$, a saturated solution of $\mathrm{NaHCO}_{3}(10 \mathrm{~mL})$ was added to the reaction. The layers were separated and the aqueous phase was extracted with dichloromethane $(3 \times 5 \mathrm{~mL})$. The organic extracts were combined and washed with brine $(10 \mathrm{~mL})$, dried over anhydrous $\mathrm{Na}_{2} \mathrm{SO}_{4}$ and concentrated under reduced pressure. The residue was purified by flash chromatography $(7 \times 0.5 \mathrm{~cm}, 1: 1$ dichloromethane/hexanes) to afford 28 as a white solid $(0.060 \mathrm{~g}$, $55 \%): R_{f}=0.31$ (5\% EtOAc/hexanes); ${ }^{1} \mathrm{H}$ NMR $\left(600 \mathrm{MHz}, \mathrm{CDCl}_{3}\right) \delta 8.33-8.27(\mathrm{~m}, 1 \mathrm{H}), 7.66(\mathrm{dd}, J=7.6,2.0$ $\mathrm{Hz}, 2 \mathrm{H}), 7.52-7.45(\mathrm{~m}, 1 \mathrm{H}), 7.40-7.34(\mathrm{~m}, 4 \mathrm{H}), 7.34-7.30(\mathrm{~m}, 2 \mathrm{H}), 6.95-6.89(\mathrm{~m}, 2 \mathrm{H}), 4.36-4.22(\mathrm{~m}, 4 \mathrm{H}), 2.08$ $(\mathrm{t}, J=4.2 \mathrm{~Hz}, 4 \mathrm{H}) ;{ }^{13} \mathrm{C}$ NMR $\left(151 \mathrm{MHz}, \mathrm{CDCl}_{3}\right) \delta$ 158.73, 141.71, 140.49, 131.38, 130.47, 129.34, 124.04, 117.44, 116.85, 114.30, 69.01, 24.25; HRMS (EI) calculated for $\mathrm{C}_{22} \mathrm{H}_{21} \mathrm{O}_{2}\left(\mathrm{M}^{+}\right) \mathrm{m} / \mathrm{z}=316.1463$, found 316.1442 .

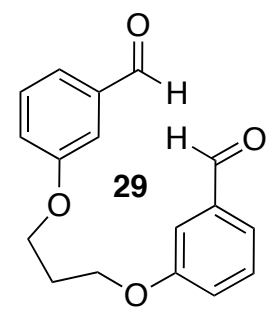

Dialdehyde 29: 1,3-Dibromopropane (2.76 g, $13.6 \mathrm{mmol})$ was added to a stirred solution of 3-hydroxybenzaldehyde (5.00 g, $40.9 \mathrm{mmol}), \mathrm{K}_{2} \mathrm{CO}_{3}(6.50 \mathrm{~g}, 47.1 \mathrm{mmol})$ and TBAI $(0.375 \mathrm{~g}, 1.01 \mathrm{mmol})$ in DMF $(75 \mathrm{~mL})$. The reaction was heated at $70{ }^{\circ} \mathrm{C}$ for $15 \mathrm{~h}$, at which point water $(100 \mathrm{~mL})$ and $1 \mathrm{M} \mathrm{HCl}(50 \mathrm{~mL})$ were added sequentially. The resulting mixture was extracted with ethyl acetate $(3 \times 50 \mathrm{~mL})$. The organic extracts were combined and washed with saturated solution of $\mathrm{NaHCO}_{3}(100 \mathrm{~mL})$ and brine $(100 \mathrm{~mL})$, dried over anhydrous $\mathrm{Na}_{2} \mathrm{SO}_{4}$, filtered and concentrated under reduced pressure. The residue was purified via flash chromatography $(16 \mathrm{~cm} \times 5.0 \mathrm{~cm}$; dichloromethane, and $2 \%$ acetone/dichloromethane $)$ to afford 2 as colorless oil. $(2.80 \mathrm{~g}, 72 \%): R_{f}=0.27$ (dichloromethane); ${ }^{1} \mathrm{H} \mathrm{NMR}\left(400 \mathrm{MHz}, \mathrm{CDCl}_{3}\right) \delta 9.80$ (s, 2H), 7.30-7.28 (m, 4H), 7.25-7.23 (m, 2H), 7.06-6.98 (m, 2H), $4.07(\mathrm{t}, J=6.1 \mathrm{~Hz}, 4 \mathrm{H}), 2.15(\mathrm{p}, J=6.1 \mathrm{~Hz}, 2 \mathrm{H}) ;{ }^{13 \mathrm{C}}$ NMR (101 MHz, $\left.\mathrm{CDCl}_{3}\right) \delta$ 192.17, 159.44, 137.88, 130.19, 123.70, 121.97, 112.82, 64.60, 29.14; HRMS (ESI) calculated for $\mathrm{C}_{17} \mathrm{H}_{17} \mathrm{O}_{4}\left([\mathrm{M}+\mathrm{H}]^{+}\right) \mathrm{m} / z=285.1127$, found 285.1124 .

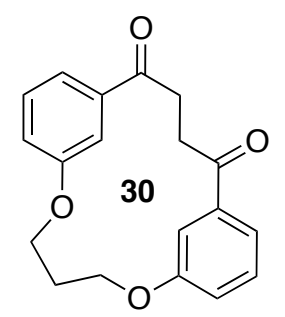

Streamlined synthesis of macrocyclic diketone 30: Vinylmagnesium chloride (1.6 $\mathrm{M}$ in $\mathrm{THF}, 2.5 \mathrm{~mL}, 4.0 \mathrm{mmol})$ was added to a stirred $0{ }^{\circ} \mathrm{C}$ solution of dialdehyde $2(0.500 \mathrm{~g}$, $1.76 \mathrm{mmol})$ in THF $(10 \mathrm{~mL})$. After $30 \mathrm{~min}$, the reaction mixture was poured into water $(50 \mathrm{~mL})$ and further diluted with $1 \mathrm{M} \mathrm{HCl}(30 \mathrm{~mL})$. The resulting mixture was 
extracted with dichloromethane $(3 \times 15 \mathrm{~mL})$. The combined organic extracts were washed with a saturated solution of $\mathrm{NaHCO}_{3}(30 \mathrm{~mL})$ and brine $(30 \mathrm{~mL})$, dried over anhydrous $\mathrm{Na}_{2} \mathrm{SO}_{4}$, and concentrated under reduced pressure. The pale yellow residue was dissolved in dichloromethane (150 $\mathrm{mL}$ ), stirred and heated to $40{ }^{\circ} \mathrm{C}$, followed by the addition of Hoveyda-Grubbs second-generation catalyst $(0.040 \mathrm{~g}, 0.060 \mathrm{mmol})$. After $2 \mathrm{~h}$, the reaction mixture was cooled to room temperature and concentrated under reduced pressure. The residue was dissolved in 1:9 methanol/dichloromethane (15 $\mathrm{mL})$ and sodium borohydride $(0.230 \mathrm{~g}, 5.88 \mathrm{mmol})$ was added. After $1 \mathrm{~h}$, the reaction mixture was poured into water $(100 \mathrm{~mL})$ and the layers were separated. The aqueous phase was extracted with dichloromethane $(2 \times 20 \mathrm{~mL})$ and the combined organic extracts were washed with water $(20 \mathrm{~mL})$, dried over anhydrous $\mathrm{Na}_{2} \mathrm{SO}_{4}$, and concentrated under reduced pressure. The residue was dissolved in dichlormethane $(20 \mathrm{~mL})$, followed by the sequential addition of $\mathrm{NaHCO}_{3}(0.270 \mathrm{~g}, 3.21 \mathrm{mmol})$ and Dess-Martin periodinane $(1.45 \mathrm{~g}, 3.20 \mathrm{mmol})$. After $2 \mathrm{~h}$, a $10 \%$ aqueous solution of $\mathrm{Na}_{2} \mathrm{~S}_{2} \mathrm{O}_{3}(50 \mathrm{~mL})$ was added and stirring was continued for $10 \mathrm{~min}$. The resulting mixture was extracted with dichloromethane $(3 \times 20 \mathrm{~mL})$. The organic extracts were combined and washed with water $(50 \mathrm{~mL})$ and brine $(50 \mathrm{~mL})$, dried over anhydrous $\mathrm{Na}_{2} \mathrm{SO}_{4}$, filtered and concentrated under reduced pressure. The residue was purified via flash chromatography $(15 \mathrm{~cm} \times 2.5 \mathrm{~cm} ; 3: 7$ ethyl acetate/hexane $)$ to give 1,4diketone 30 as a beige solid ( $0.120 \mathrm{~g}, 22 \%$, over 4 steps): $R_{f}=0.38$ (2:3 ethyl acetate/hexane); ${ }^{1} \mathrm{H}$ NMR $\left(600 \mathrm{MHz} \mathrm{CDCl}_{3}\right) \delta 7.42(\mathrm{dd}, J=7.7,1.3 \mathrm{~Hz}, 2 \mathrm{H}), 7.36-7.29(\mathrm{~m}, 2 \mathrm{H}), 7.24-7.20(\mathrm{~m}, 2 \mathrm{H}), 7.10(\mathrm{ddd}, J=8.1$, 2.6, $1.0 \mathrm{~Hz}, 2 \mathrm{H}), 4.34(\mathrm{t}, J=6.1 \mathrm{~Hz}, 4 \mathrm{H}), 3.11(\mathrm{~s}, 4 \mathrm{H}), 2.19(\mathrm{p}, J=6.1 \mathrm{~Hz}, 2 \mathrm{H}) ;{ }^{13} \mathrm{C} \mathrm{NMR}\left(151 \mathrm{MHz}, \mathrm{CDCl}_{3}\right)$ ठ 200.85, 159.14, 138.03, 130.43, 121.57, 121.39, 117.10, 66.38, 36.42, 29.09.

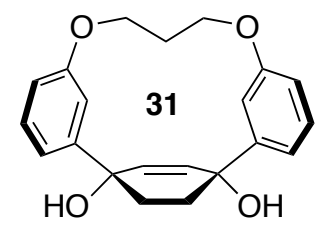

Cyclohex-2-ene-1,4-diol 31: Vinylmagnesium chloride (1.6 M in THF, $0.45 \mathrm{~mL}, 0.70$ $\mathrm{mmol})$ was added to a stirred solution of 1,4-diketone $30(0.100 \mathrm{~g}, 0.322 \mathrm{mmol})$, in $\mathrm{THF}(4 \mathrm{~mL})$ at $65^{\circ} \mathrm{C}$. After $30 \mathrm{~min}$. , the reaction mixture was cooled to room temperature, poured into water $(20 \mathrm{~mL})$, and further diluted with $1 \mathrm{M} \mathrm{HCl}(10 \mathrm{~mL})$. The resulting mixture was extracted with dichloromethane $(3 \times 10 \mathrm{~mL})$. The combined organic extracts were washed with a saturated solution of $\mathrm{NaHCO}_{3}(30 \mathrm{~mL})$ and brine $(30 \mathrm{~mL})$, dried over anhydrous $\mathrm{Na}_{2} \mathrm{SO}_{4}$ and concentrated under reduced pressure. The pale yellow residue was dissolved in dichloromethane (10 $\mathrm{mL})$, the Grubbs second-generation catalyst $(0.007 \mathrm{~g}, 0.008 \mathrm{mmol})$ was added, and the reaction was heated to $40{ }^{\circ} \mathrm{C}$. After $2 \mathrm{~h}$, the reaction was cooled to room temperature and the solvent was removed 
under reduced pressure. The brown residue was purified by flash chromatography $(15 \times 1.3 \mathrm{~cm}, 3: 2$ EtOAc/hexane) to give compound 37 as an off-white solid (0.065 g, 60\%); $R_{f}=0.41$ (7:3 EtOAc/hexane); ${ }^{1} \mathrm{H}$ NMR (400 MHz, $\left.\mathrm{CDCl}_{3}\right) \delta$ 7.36-7.30 (m, 4H), 7.03-6.99 (m, 2H), 6.92-6.84 (m, 2H), $6.14(\mathrm{~s}, 2 \mathrm{H}), 4.46-$ $4.30(\mathrm{~m}, 2 \mathrm{H}), 4.29-4.23(\mathrm{~m}, 2 \mathrm{H}), 2.29-2.08(\mathrm{~m}, 6 \mathrm{H}), 1.84-1.71(\mathrm{~m}, 2 \mathrm{H}) ;{ }^{13} \mathrm{C} \mathrm{NMR}\left(101 \mathrm{MHz}, \mathrm{CDCl}_{3}\right) \delta$ 158.88, 146.95, 142.95, 129.36, 119.04, 115.62, 114.07, 113.62, 76.93, 65.44, 37.24, 27.78; HRMS (ESI) calculated for $\left.\mathrm{C}_{21} \mathrm{H}_{21} \mathrm{O}_{3}\left(\left[\mathrm{M}-\left(\mathrm{H}_{2} \mathrm{O}\right)\right]+\mathrm{H}\right]^{+}\right) \mathrm{m} / z=321.1491$, found 321.1493 .

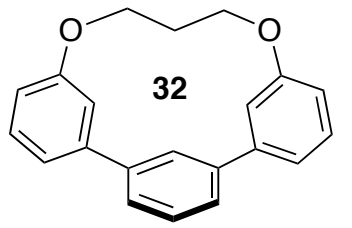

1,5-dioxa[5](3,3")m-Terphenylophane (32): para-Toluensulfonic acid monohydrate $(0.060 \mathrm{~g}, 0.31 \mathrm{mmol})$ was added to a stirred $60{ }^{\circ} \mathrm{C}$ of $31(0.012 \mathrm{~g}$, $0.038 \mathrm{mmol})$ in toluene $(2.5 \mathrm{~mL})$. After $3 \mathrm{~h}$, the reaction was heated to $70{ }^{\circ} \mathrm{C}$ for an additional $1 \mathrm{~h}$, followed by the addition of a saturated solution of $\mathrm{NaHCO}_{3}(10 \mathrm{~mL})$. The layers were separated and the aqueous phase was extracted with dichloromethane $(3 \times 5 \mathrm{~mL})$. The organic extracts were combined and washed with brine $(10 \mathrm{~mL})$, dried over anhydrous $\mathrm{Na}_{2} \mathrm{SO}_{4}$ and concentrated under reduced pressure. The residue was purified by flash chromatography $(7 \times 0.5 \mathrm{~cm}, 1: 1$ dichloromethane/hexanes) to afford 32 as a white solid $(0.004 \mathrm{~g}, 40 \%): R_{f}=0.41$ (2:3 dichloromethane /hexanes); ${ }^{1} \mathrm{H}$ NMR (600 MHz, $\left.\mathrm{CDCl}_{3}\right) \delta 7.62$ (dd, J = 7.5, $\left.2.0 \mathrm{~Hz}, 2 \mathrm{H}\right), 7.50$ (d, J = 2.1 Hz, 1H), 7.46-7.40 (m, 1H), 7.35-7.29 (m, 2H), 7.28 (s, 1H), 7.07-7.02 (m, 2H), $6.92(\mathrm{dd}, J=8.2,2.8 \mathrm{~Hz}, 2 \mathrm{H}), 4.36-4.19(\mathrm{~m}, 4 \mathrm{H})$, 2.65 (s, 2H); ${ }^{13} \mathrm{C}$ NMR $\left(151 \mathrm{MHz}, \mathrm{CDCl}_{3}\right) \delta$ 157.24, 144.91, 142.84, 142.64, 129.70, 127.63, 123.74, 118.28, 117.98, 116.15, 64.23, 24.77; HRMS (EI) calculated for $\mathrm{C}_{21} \mathrm{H}_{18} \mathrm{O}_{2}\left(\mathrm{M}^{+}\right) \mathrm{m} / z=302.1307$, found 302.1336.

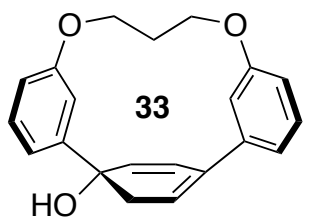

Tin(II) chloride dihydrate $(0.053 \mathrm{~g}, 0.230 \mathrm{mmol})$ was added to a stirred solution of $31(0.008 \mathrm{~g}, 0.023 \mathrm{mmol})$ in $1: 1 \mathrm{THF} / \mathrm{PhMe}(4 \mathrm{~mL})$ at $80^{\circ} \mathrm{C}$. After $12 \mathrm{~h}$, the reaction was cooled to room temperature and $3 \mathrm{M} \mathrm{NaOH}(5 \mathrm{~mL})$ was added, followed by dichloromethane $(10 \mathrm{~mL})$. The layers were separated and the aqueous phase was extracted with dichloromethane $(3 \times 5 \mathrm{~mL})$. The combined organic extracts was washed with brine $(30 \mathrm{~mL})$, dried over anhydrous $\mathrm{Na}_{2} \mathrm{SO}_{4}$ and concentrated under reduced pressure. The off-white residue was purified by flash chromatography $(4.0 \times 0.7 \mathrm{~cm}$, dichloromethane to $2 \%$ acetone/dichloromethane $)$ to give compound 33 as colorless solid (0.006 g, 78\%); $R_{f}=0.41$ (1\% acetone/dichloromethane); ${ }^{1} \mathrm{H}$ NMR (600 $\left.\mathrm{MHz}_{2} \mathrm{CDCl}_{3}\right) \delta 7.41(\mathrm{dd}, J=2.5,1.7 \mathrm{~Hz}, 1 \mathrm{H}), 7.34-7.24(\mathrm{~m}, 2 \mathrm{H}), 7.22-7.15(\mathrm{~m}, 1 \mathrm{H}), 6.91(\mathrm{ddd}, J=7.8,2.6$, $1.2 \mathrm{~Hz}, 1 \mathrm{H}), 6.84-6.80(\mathrm{~m}, 1 \mathrm{H}), 6.79-6.72(\mathrm{~m}, 2 \mathrm{H}), 6.36(\mathrm{dd}, J=9.6,0.9 \mathrm{~Hz}, 1 \mathrm{H}), 6.12(\mathrm{dt}, J=9.6,1.3 \mathrm{~Hz}$, $1 \mathrm{H}), 5.66(\mathrm{ddd}, J=7.0,2.8,1.4 \mathrm{~Hz}, 1 \mathrm{H}), 4.52-4.40(\mathrm{~m}, 1 \mathrm{H}), 4.41-4.15(\mathrm{~m}, 3 \mathrm{H}), 2.97-2.84(\mathrm{~m}, 1 \mathrm{H}), 2.71(\mathrm{ddd}$, 
$J=16.0,7.0,1.9 \mathrm{~Hz}, 1 \mathrm{H}), 2.16(\mathrm{~s}, 1 \mathrm{H}), 2.06-1.91(\mathrm{~m}, 1 \mathrm{H}), 1.88-1.76(\mathrm{~m}, 1 \mathrm{H}) ;{ }^{13} \mathrm{C} \mathrm{NMR}\left(101 \mathrm{MHz}, \mathrm{CDCl}_{3}\right) \delta$ 156.98, 156.95, 145.10, 142.78, 139.09, 135.73, 130.31, 130.20, 129.11, 124.46, 120.22, 117.53, 116.56, 116.36, 116.05, 111.99, 75.50, 65.96, 64.25, 39.18, 26.69; HRMS (EI) calculated for $\mathrm{C}_{21} \mathrm{H}_{20} \mathrm{O}_{3}\left(\mathrm{M}^{+}\right) \mathrm{m} / z=320.1412$, found 320.1410

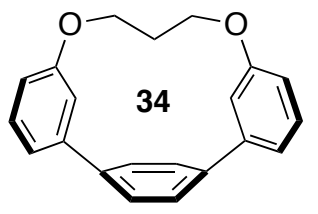
1,5-dioxa[5](3,3")p-terphenylenophane (34) (Table 1, entry 9): Burgess reagent (0.126 g, $0.530 \mathrm{mmol})$ was added to a stirred solution of $31(0.044 \mathrm{~g}, 0.130 \mathrm{mmol})$ in toluene $(2.5 \mathrm{~mL})$ at $80{ }^{\circ} \mathrm{C}$. After $15 \mathrm{~min}$., the reaction was cooled to room temperature, water $(20 \mathrm{~mL})$ was added, and the resulting mixture was stirred for $5 \mathrm{~min}$. The layers were separated and the mixture was extracted with dichloromethane $(3 \times 10 \mathrm{~mL})$. The organic extracts were combined and washed with brine $(10 \mathrm{~mL})$, dried over anhydrous $\mathrm{MgSO}_{4}$ and concentrated under reduced pressure. The residue was purified by flash chromatography $(12 \times 1.3 \mathrm{~cm}, 1: 1$ dichloromethane/hexanes) to afford 34 as a white solid $(0.023 \mathrm{~g}, 58 \%): \quad R_{\mathrm{f}}=0.43(2: 3$ dichloromethane/hexane); ${ }^{1} \mathrm{H}$ NMR $\left(600 \mathrm{MHz}, \mathrm{CDCl}_{3}\right) \delta 7.42(\mathrm{~s}, 4 \mathrm{H}), 7.33-7.26$ (m, 2H), 7.25-7.21 (m, 2H), $6.72(\mathrm{dd}, J=8.3,2.8 \mathrm{~Hz}, 2 \mathrm{H}), 5.35(\mathrm{~s}, 2 \mathrm{H}), 4.12-3.81(\mathrm{~m}, 4 \mathrm{H}), 1.96-1.86(\mathrm{~m}, 2 \mathrm{H}) ;{ }^{13} \mathrm{C}$ NMR $(151 \mathrm{MHz}$, $\left.\mathrm{CDCl}_{3}\right) \delta 157.25,145.19,145.13,131.75,130.53,118.50,115.48,115.42,64.67,25.16$; HRMS (EI) calculated for $\mathrm{C}_{21} \mathrm{H}_{18} \mathrm{O}_{2}\left(\mathrm{M}^{+}\right) m / z=302.1307$, found 302.1336 .

Alternate procedure for 34 (Table 1 entry 8): Trifluoromethanesulfonic anhydride $0.088 \mathrm{~g}, 0.31 \mathrm{mmol}$ ) and pyridine $(0.5 \mathrm{~mL})$ were added to a stirred solution of $33(0.020 \mathrm{~g}, 0.062 \mathrm{mmol})$ in dichloromethane (2 $\mathrm{mL})$ at $0{ }^{\circ} \mathrm{C}$. After $30 \mathrm{~min}$., the cooling bath was removed and the reaction was warmed to room temperature, poured into water $(10 \mathrm{~mL})$, and further diluted by $1 \mathrm{M} \mathrm{HCl}(5 \mathrm{~mL})$. The layers were separated and the aqueous layer was extracted with dichloromethane $(2 \times 10 \mathrm{~mL})$. The combined organic extracts were washed with saturated solution of $\mathrm{NaHCO}_{3}(10 \mathrm{~mL})$, brine $(10 \mathrm{~mL})$, dried over anhydrous $\mathrm{MgSO}_{4}$ and concentrated under reduced pressure. The residue was purified by flash chromatograph $(12 \times 0.5 \mathrm{~cm}, 2: 3$ dichloromethane/hexanes) to afford 34 as a white solid (0.003 $\mathrm{g}, 16 \%)$. 


\section{${ }^{1} \mathrm{H}$ and ${ }^{13} \mathrm{C}$ NMR Spectra (listed in numerical order)}
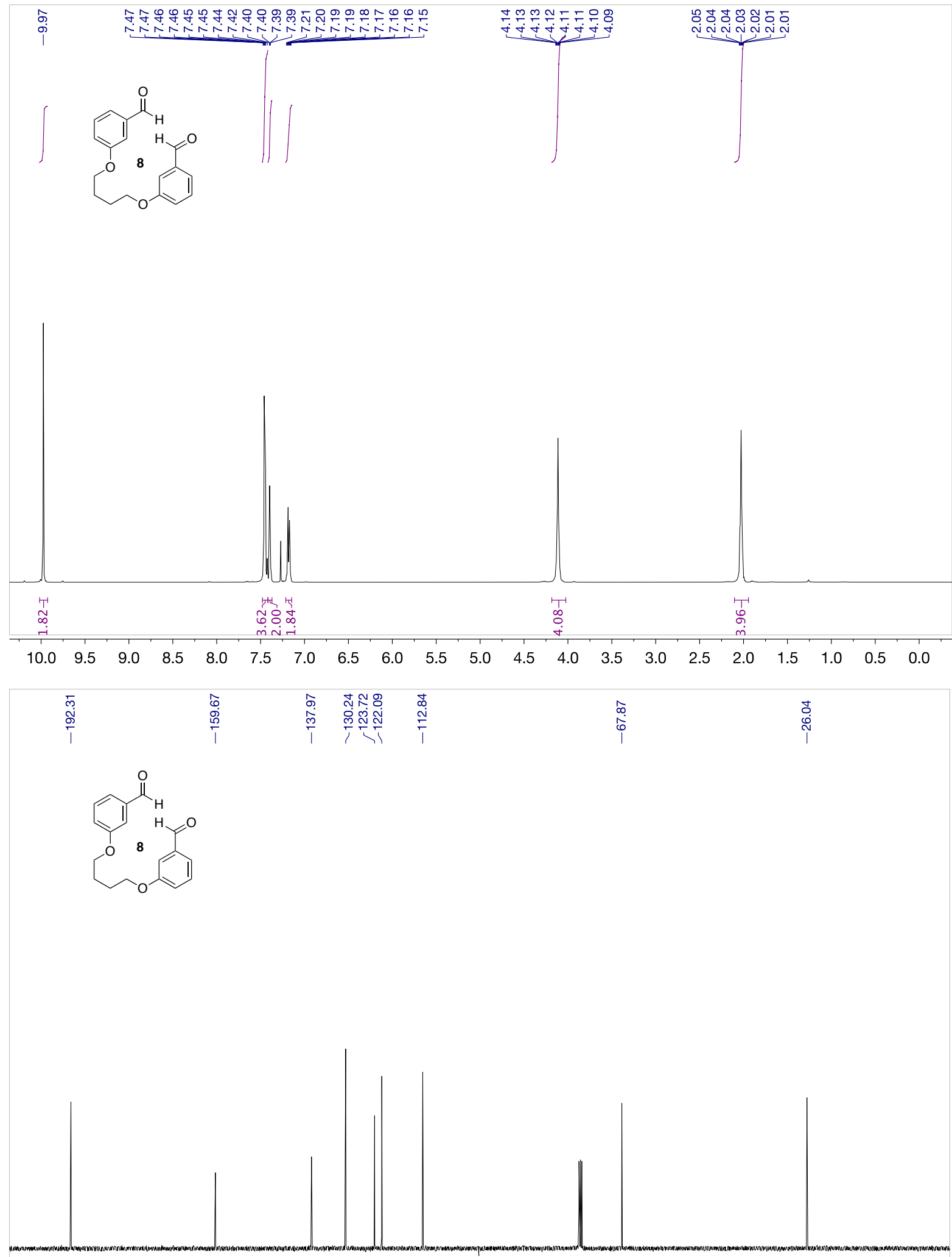



SI-16 

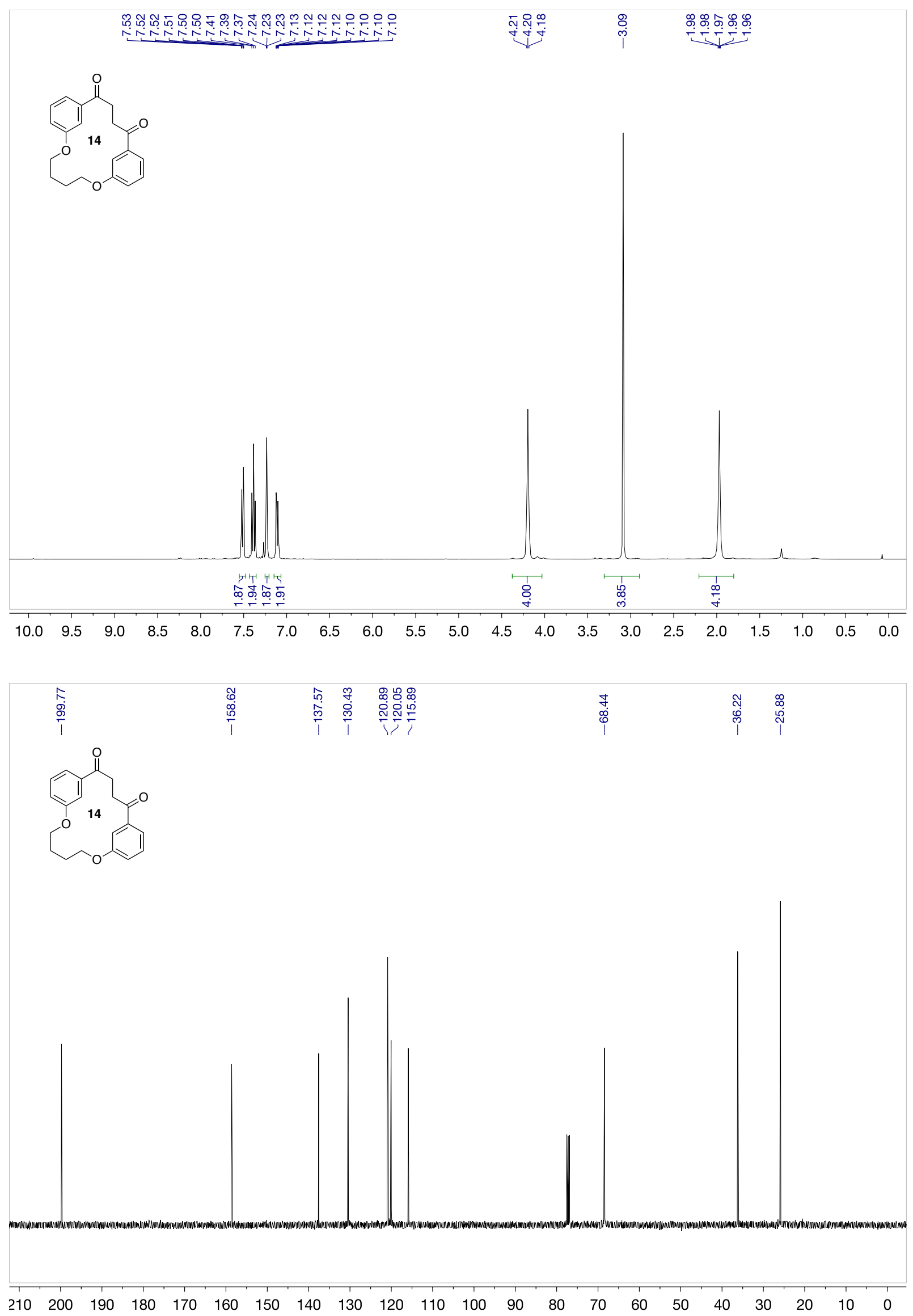

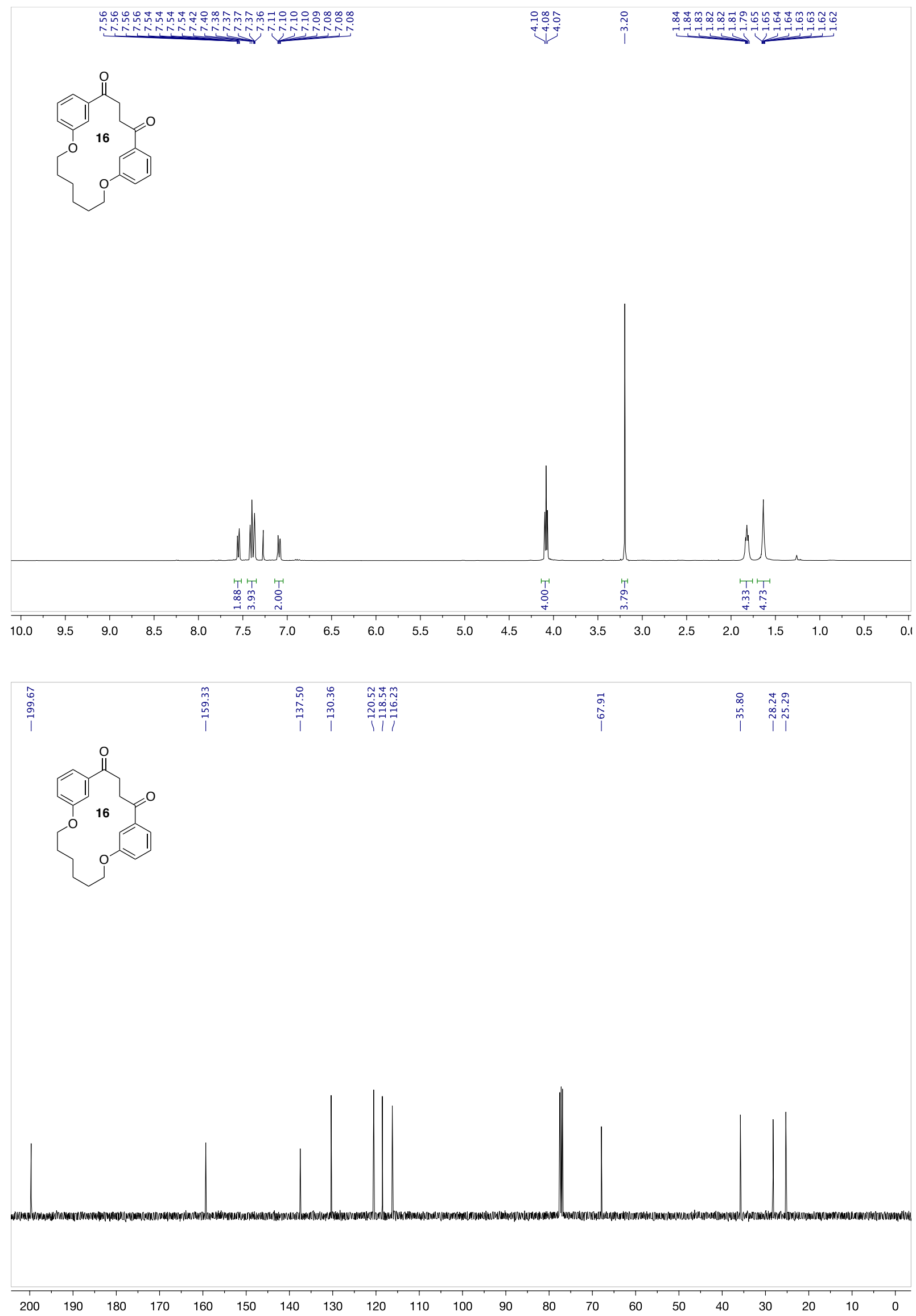

SI-18 

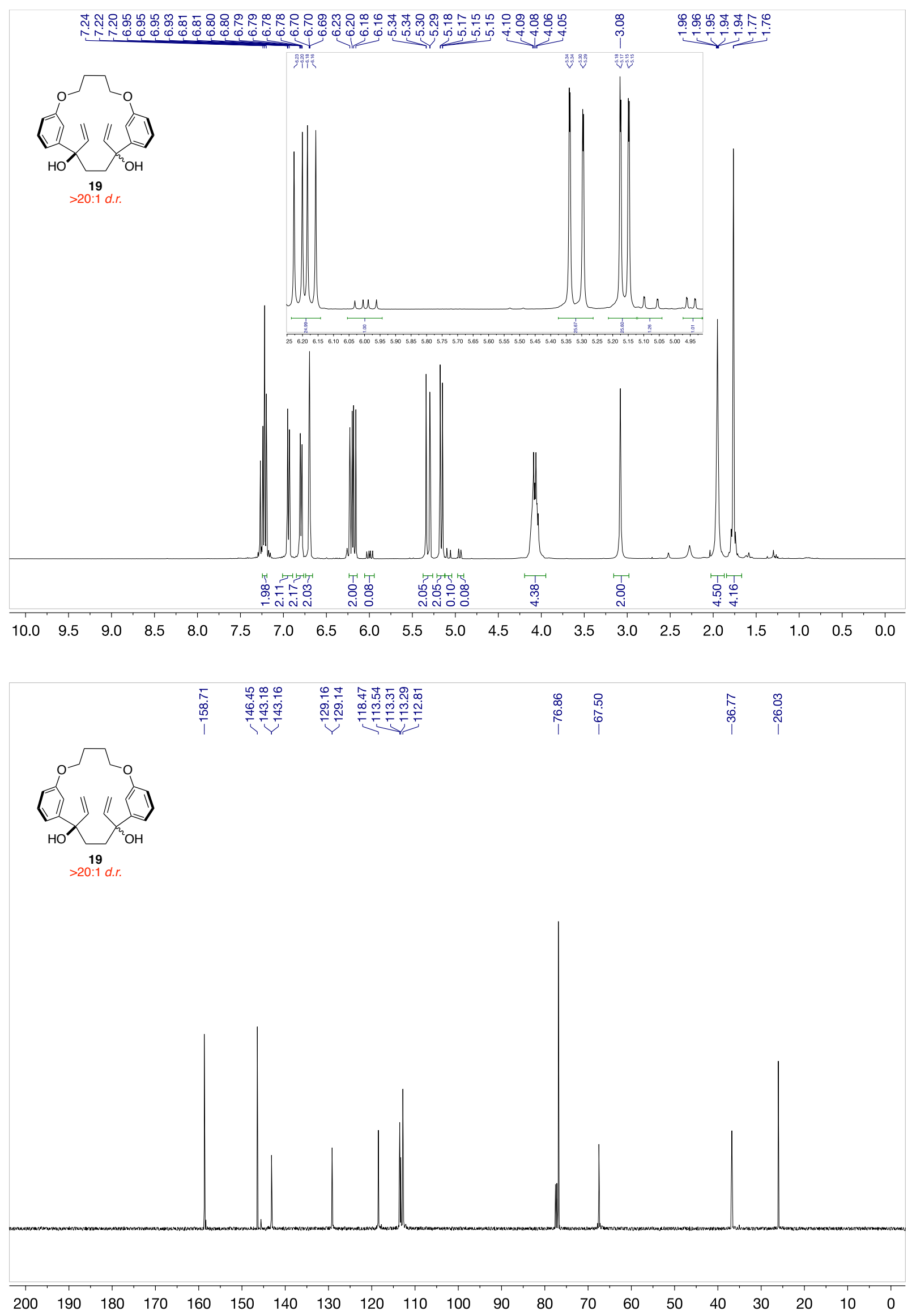


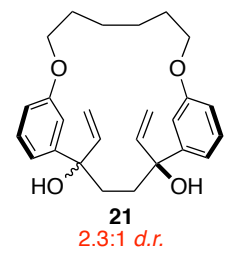
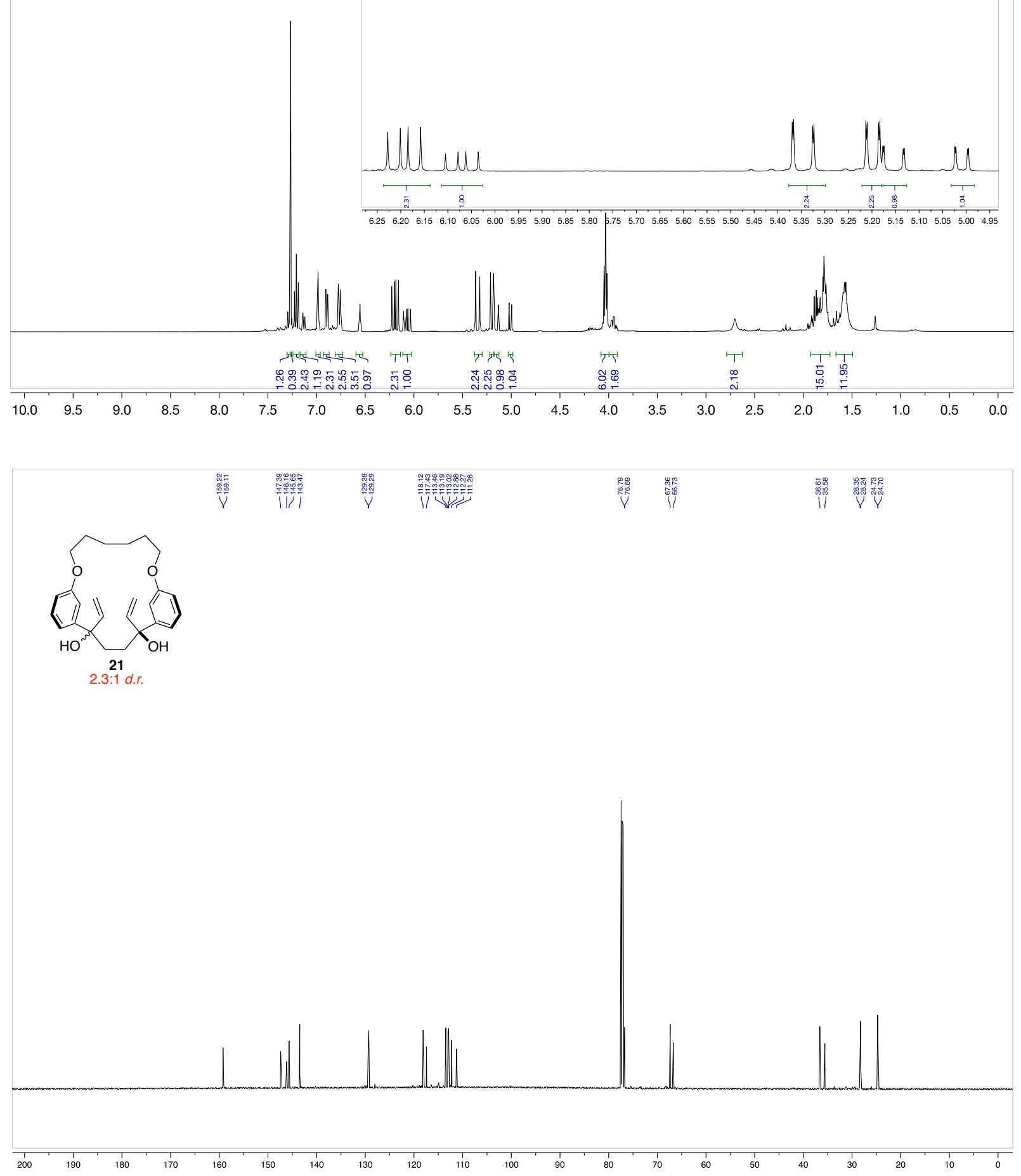

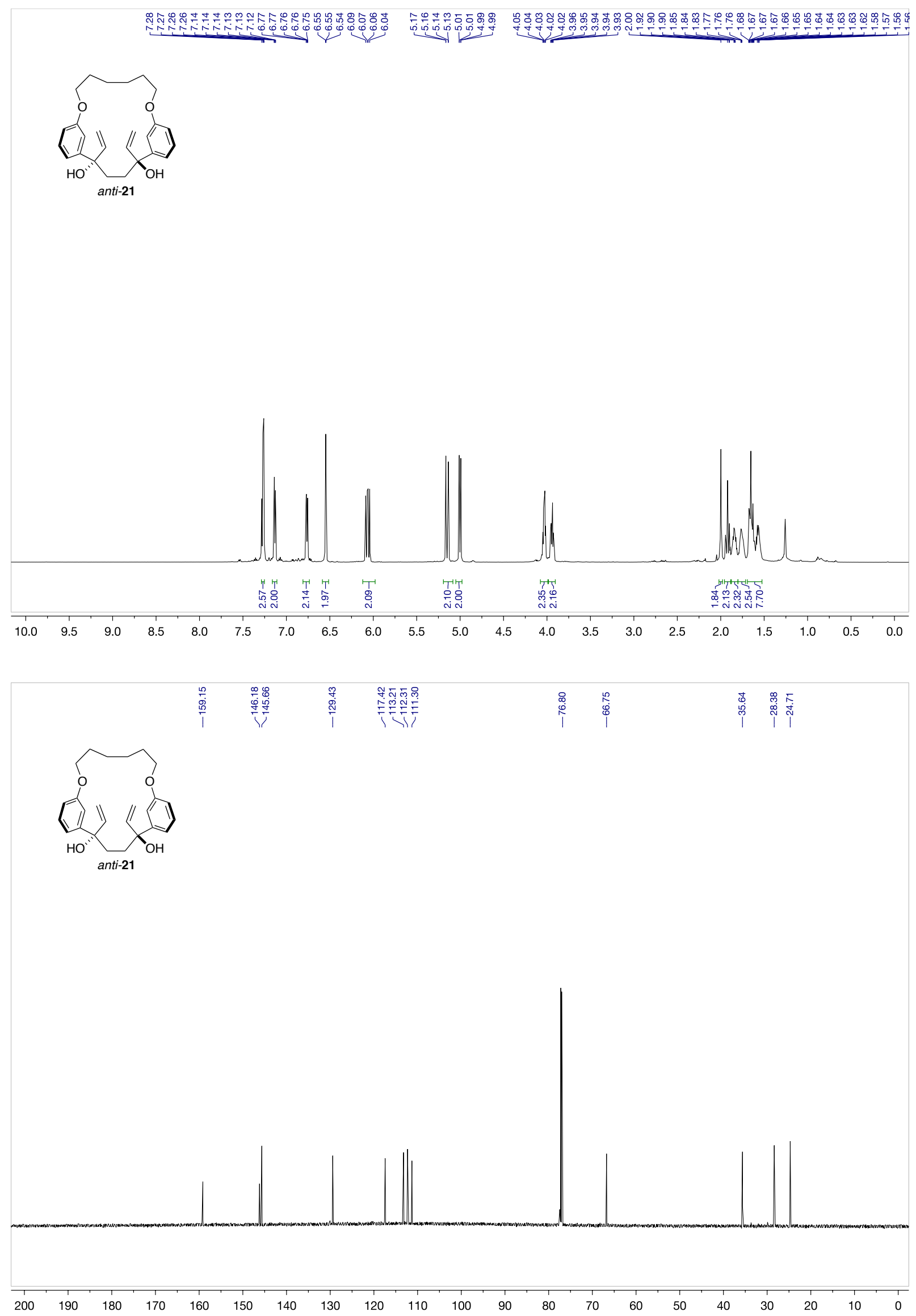

SI-21 


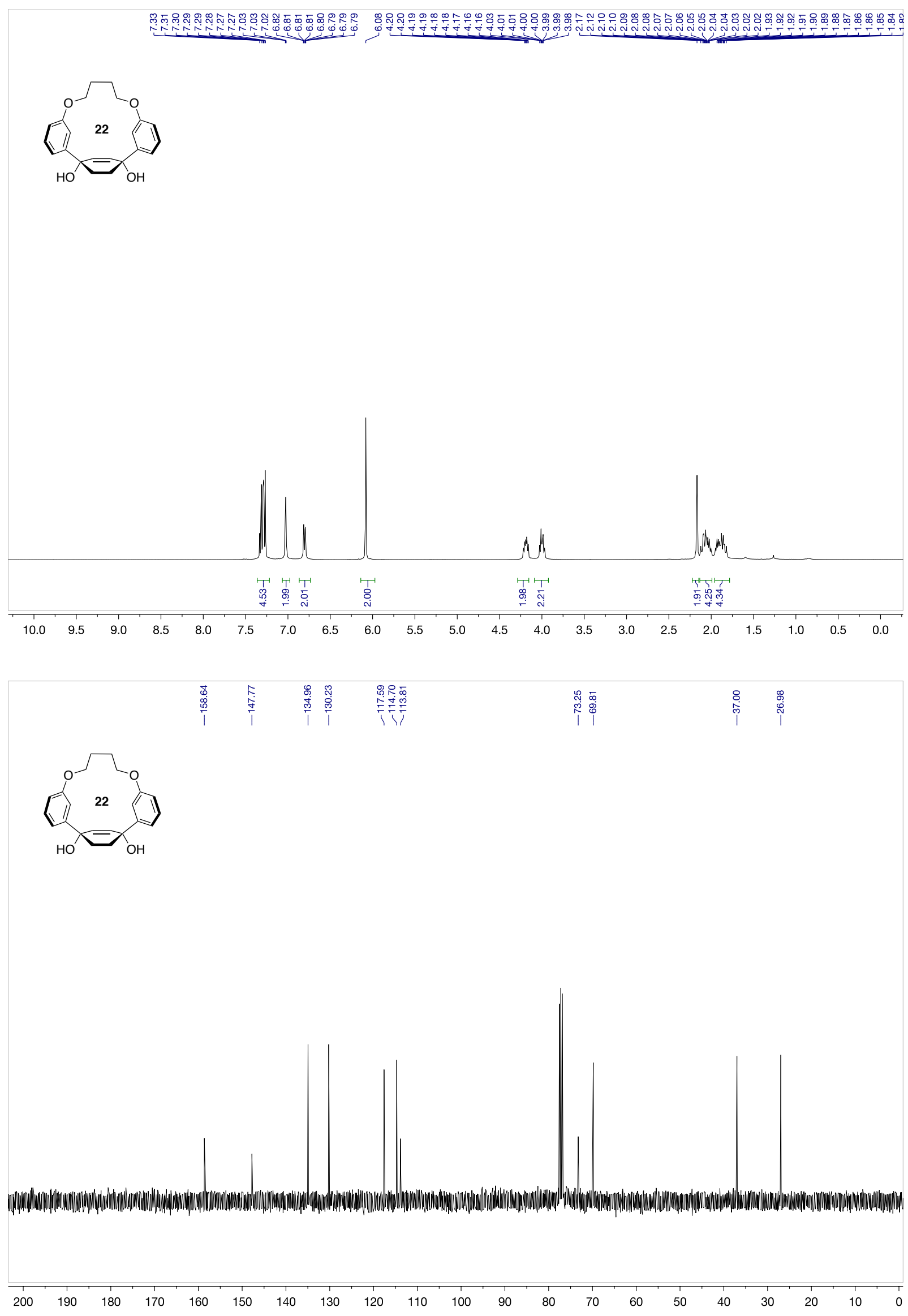



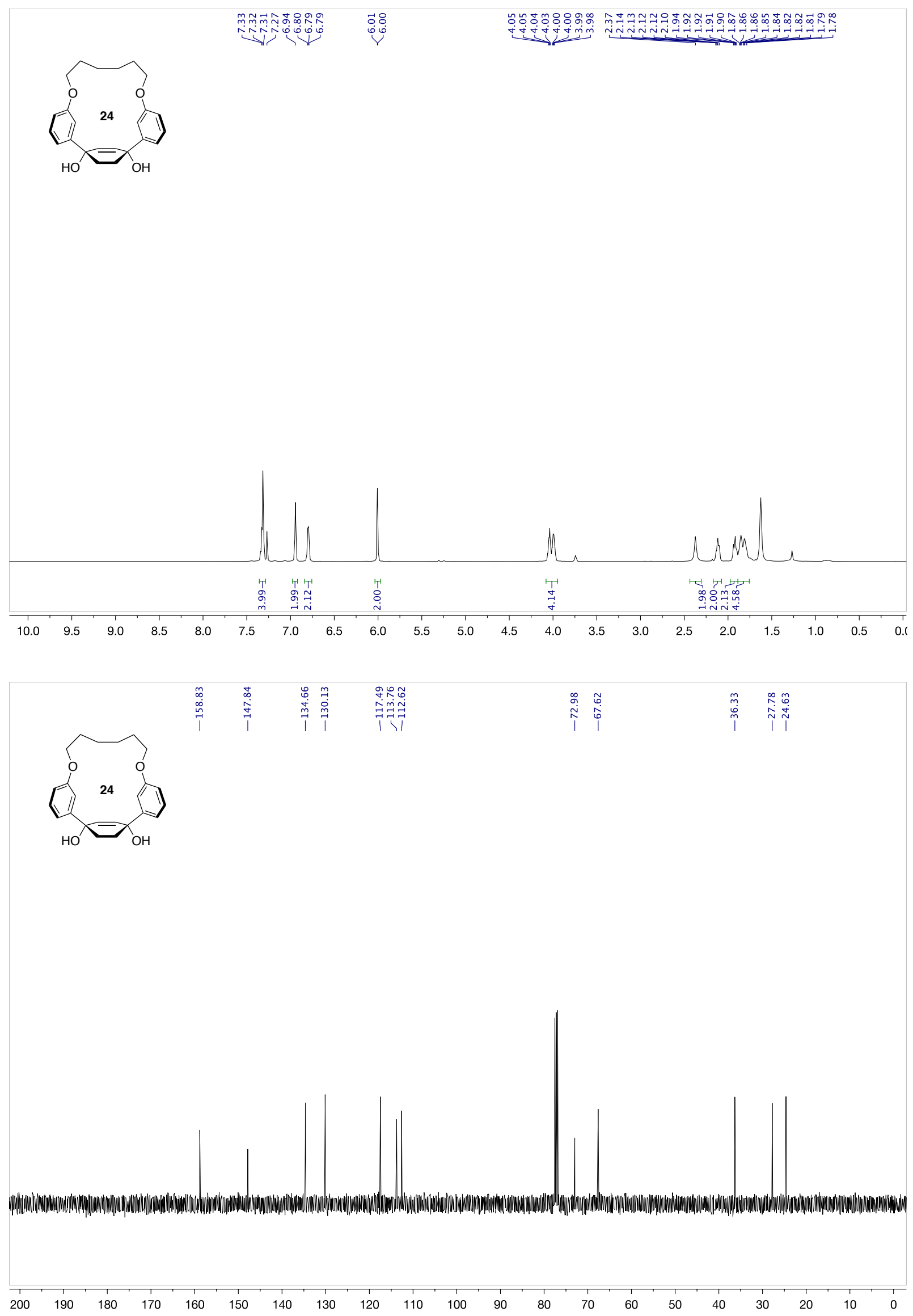


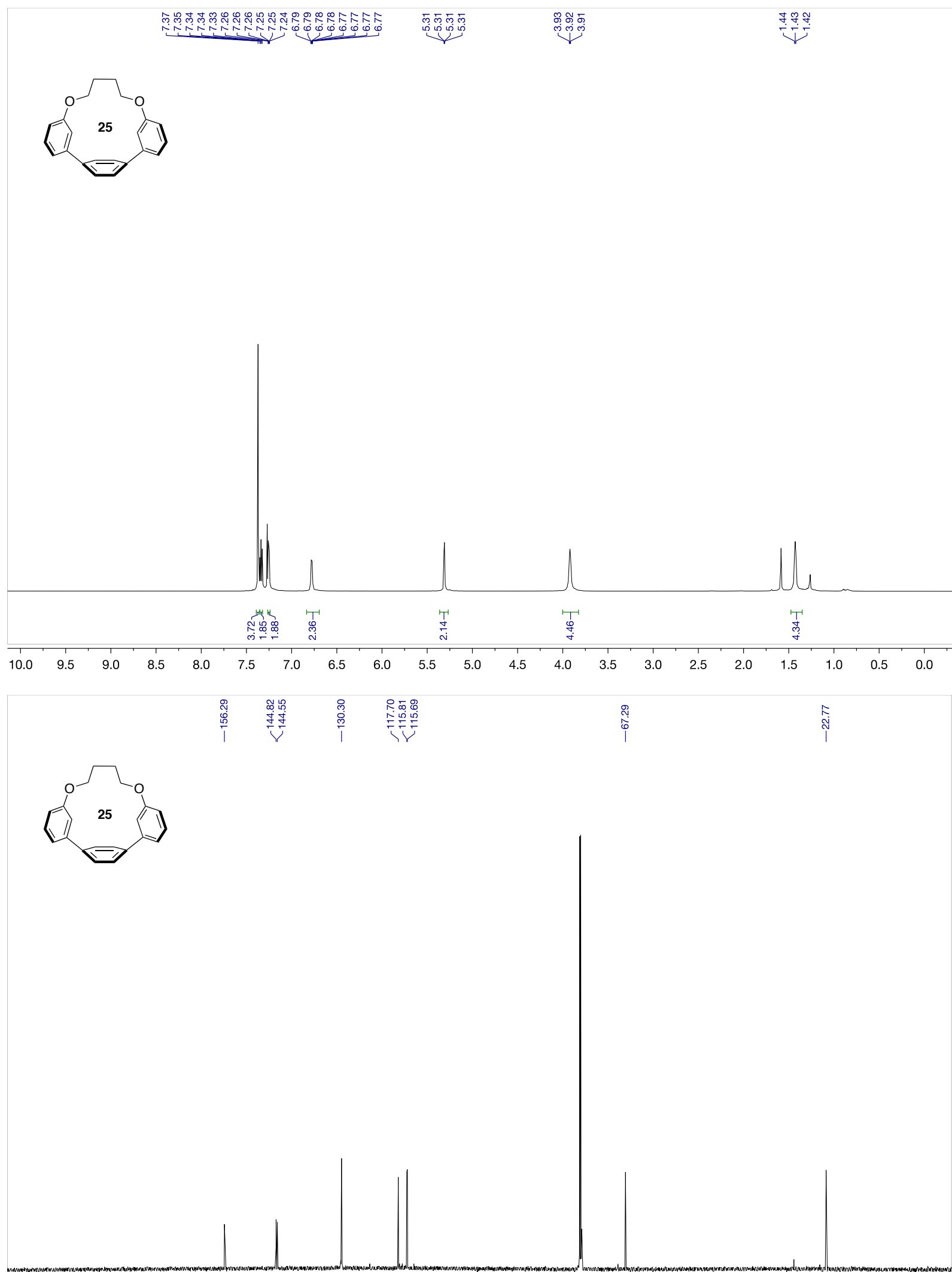

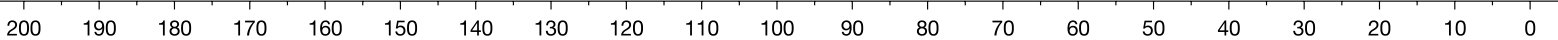



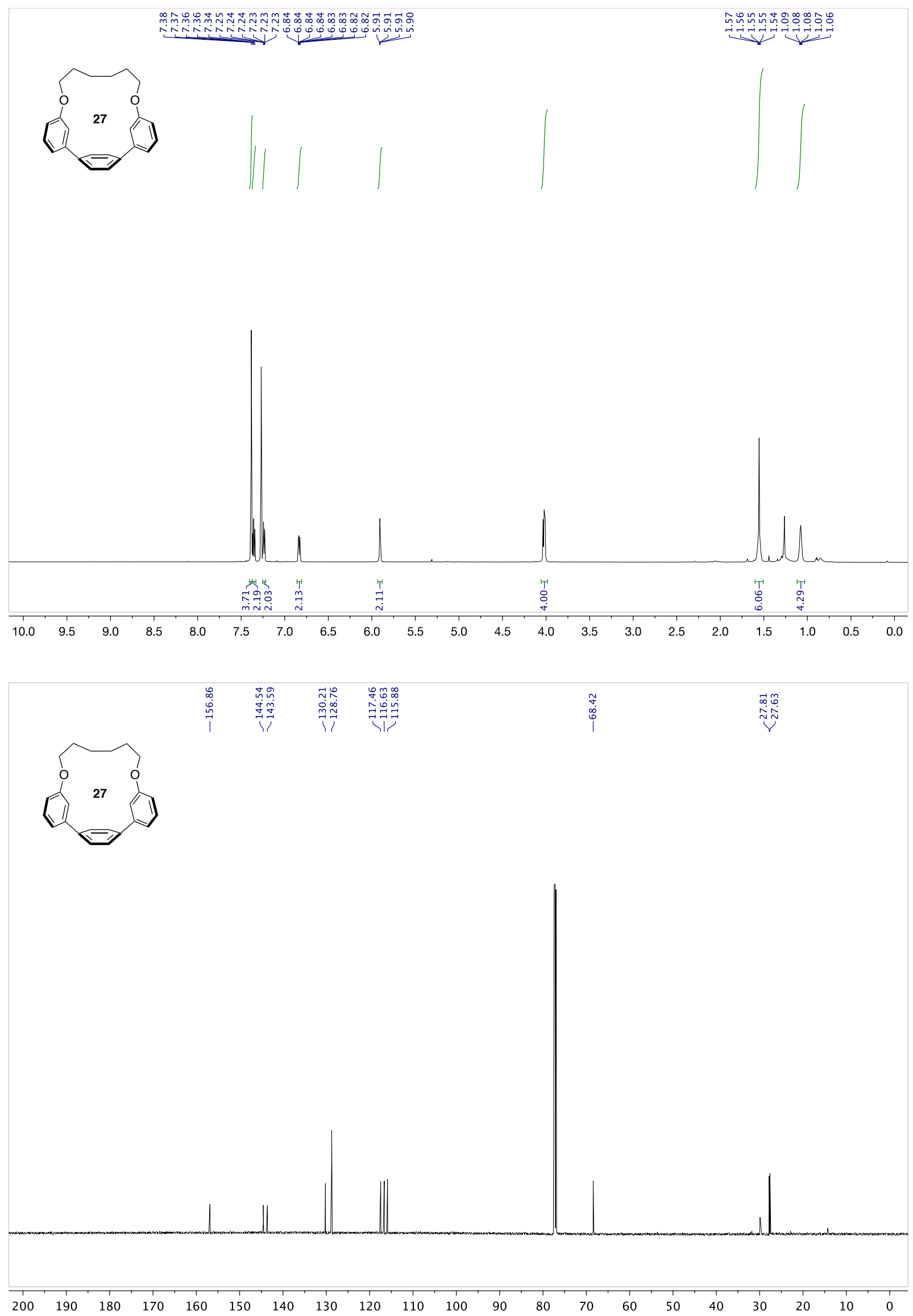

SI-25 

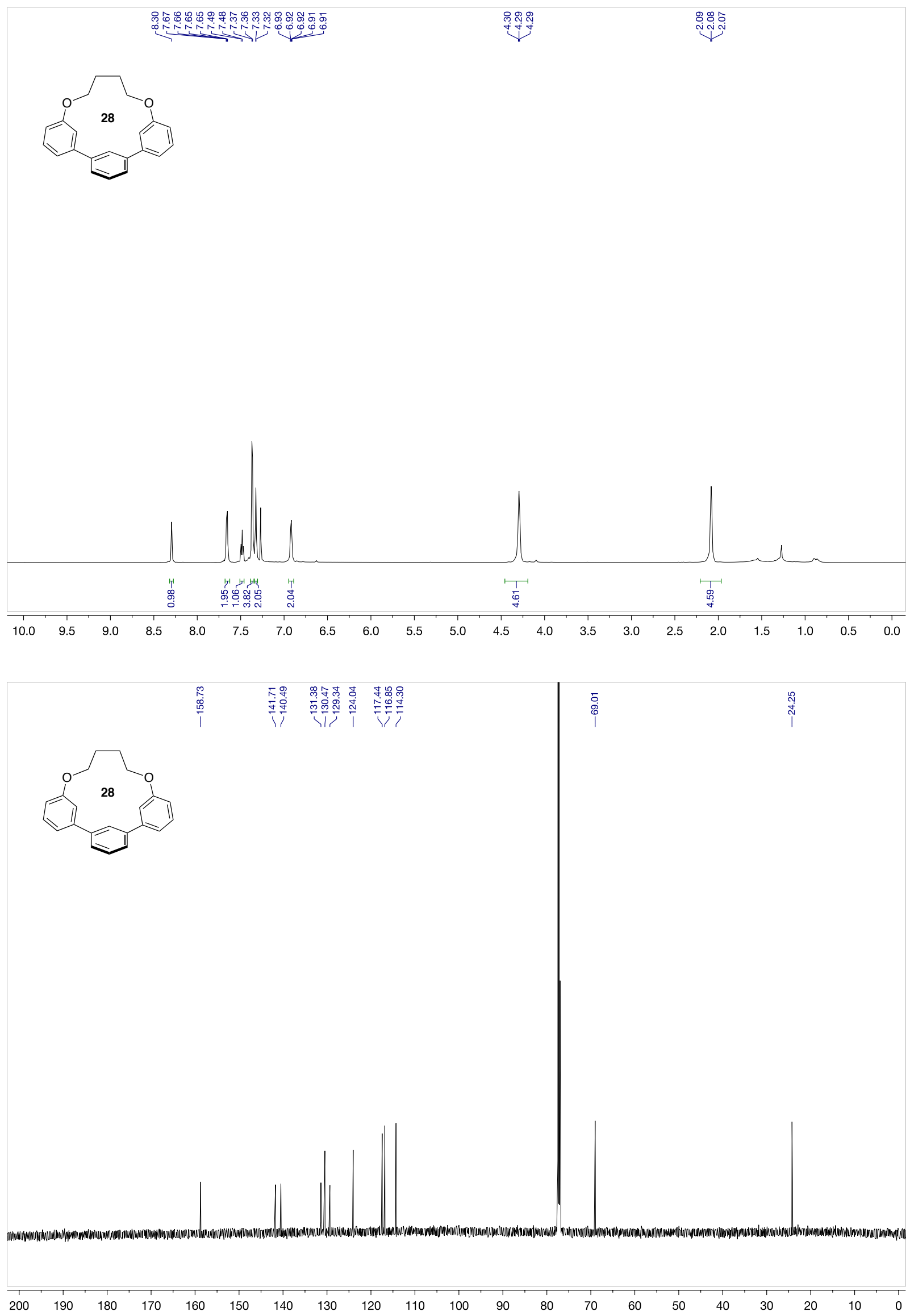

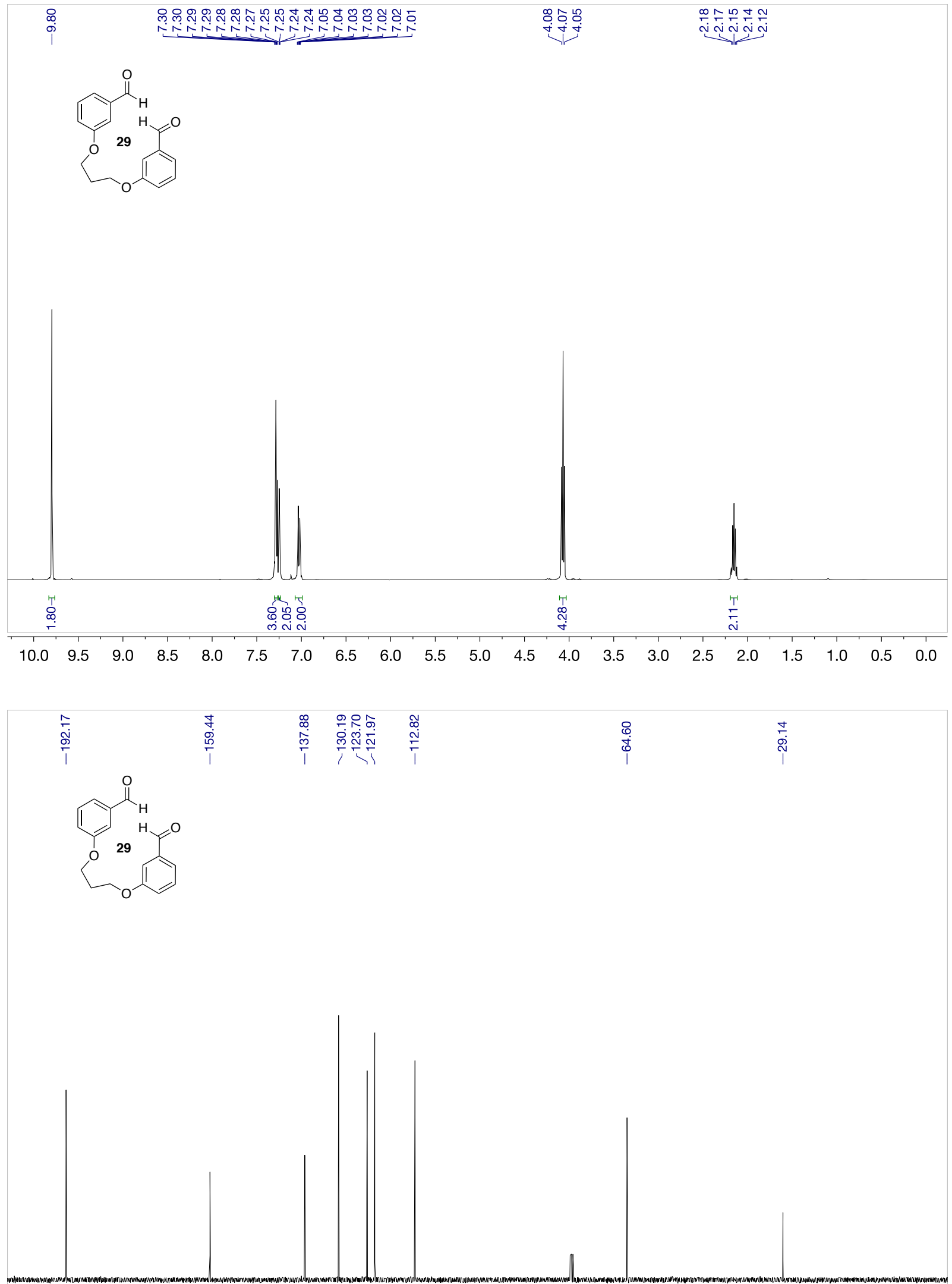

$\begin{array}{lllllllllllllllllllll}200 & 190 & 180 & 170 & 160 & 150 & 140 & 130 & 120 & 110 & 100 & 90 & 80 & 70 & 60 & 50 & 40 & 30 & 20 & 10 & 0\end{array}$ 

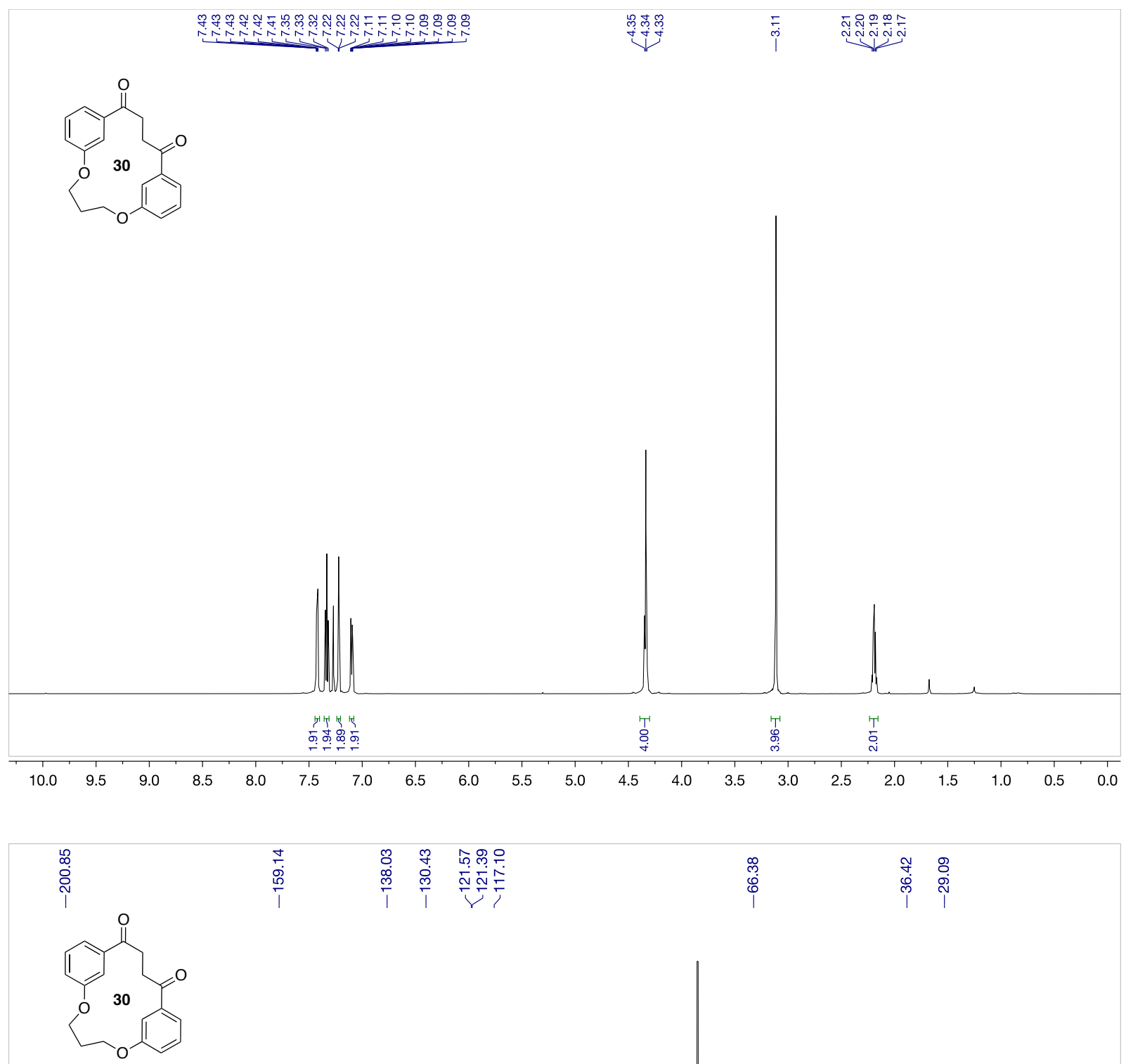

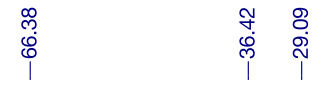
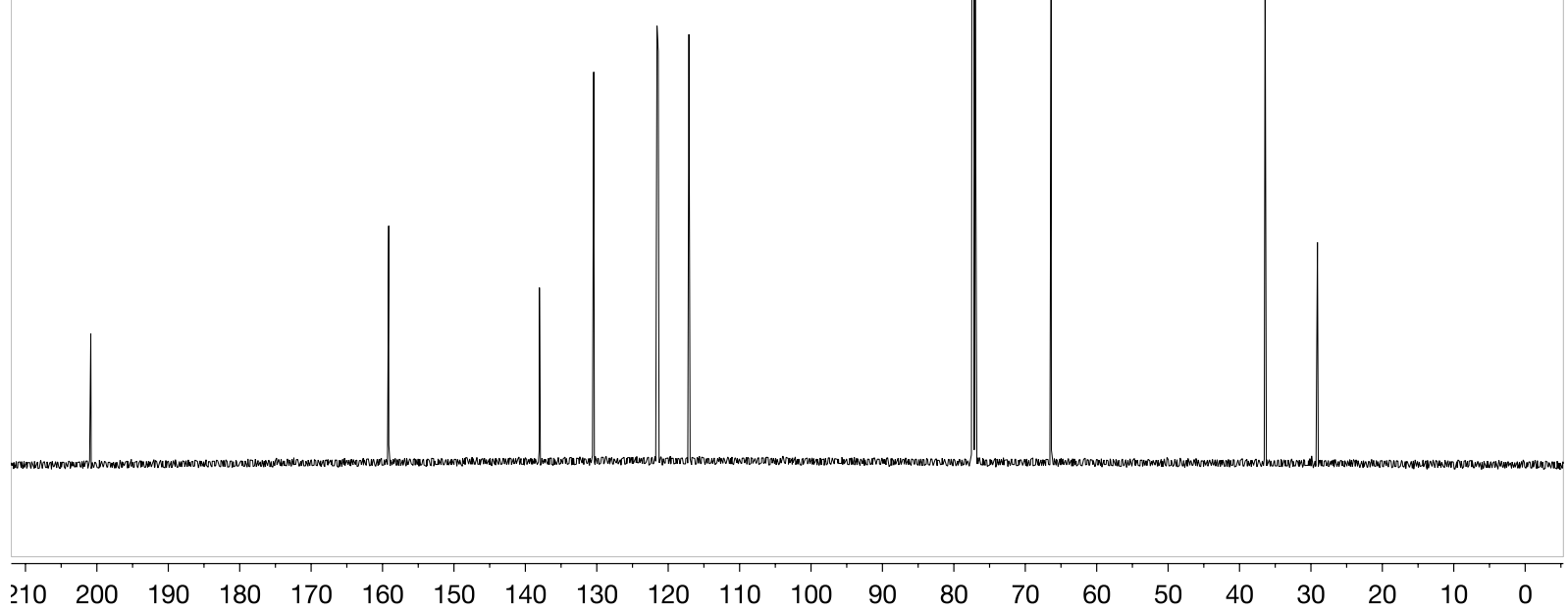

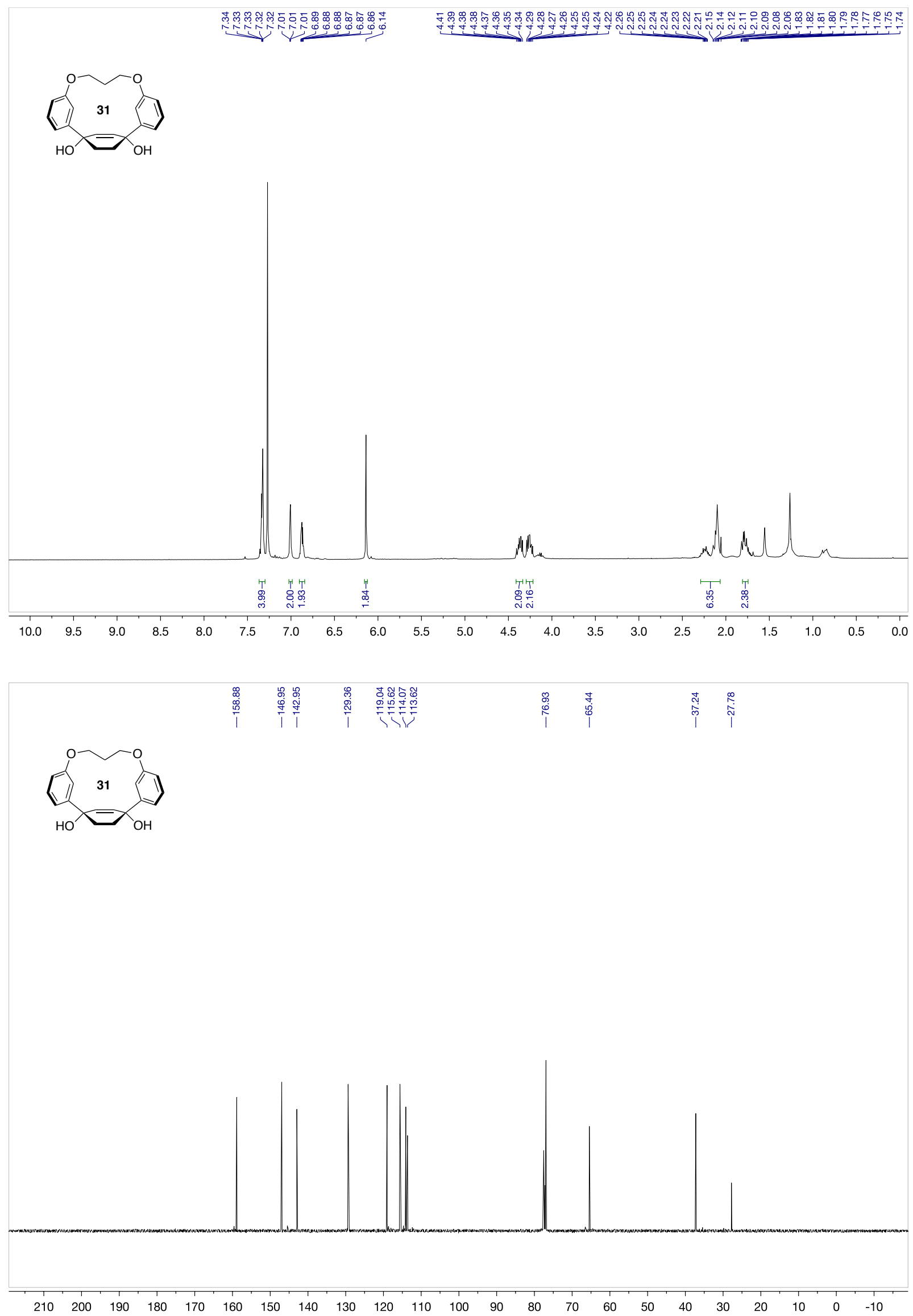

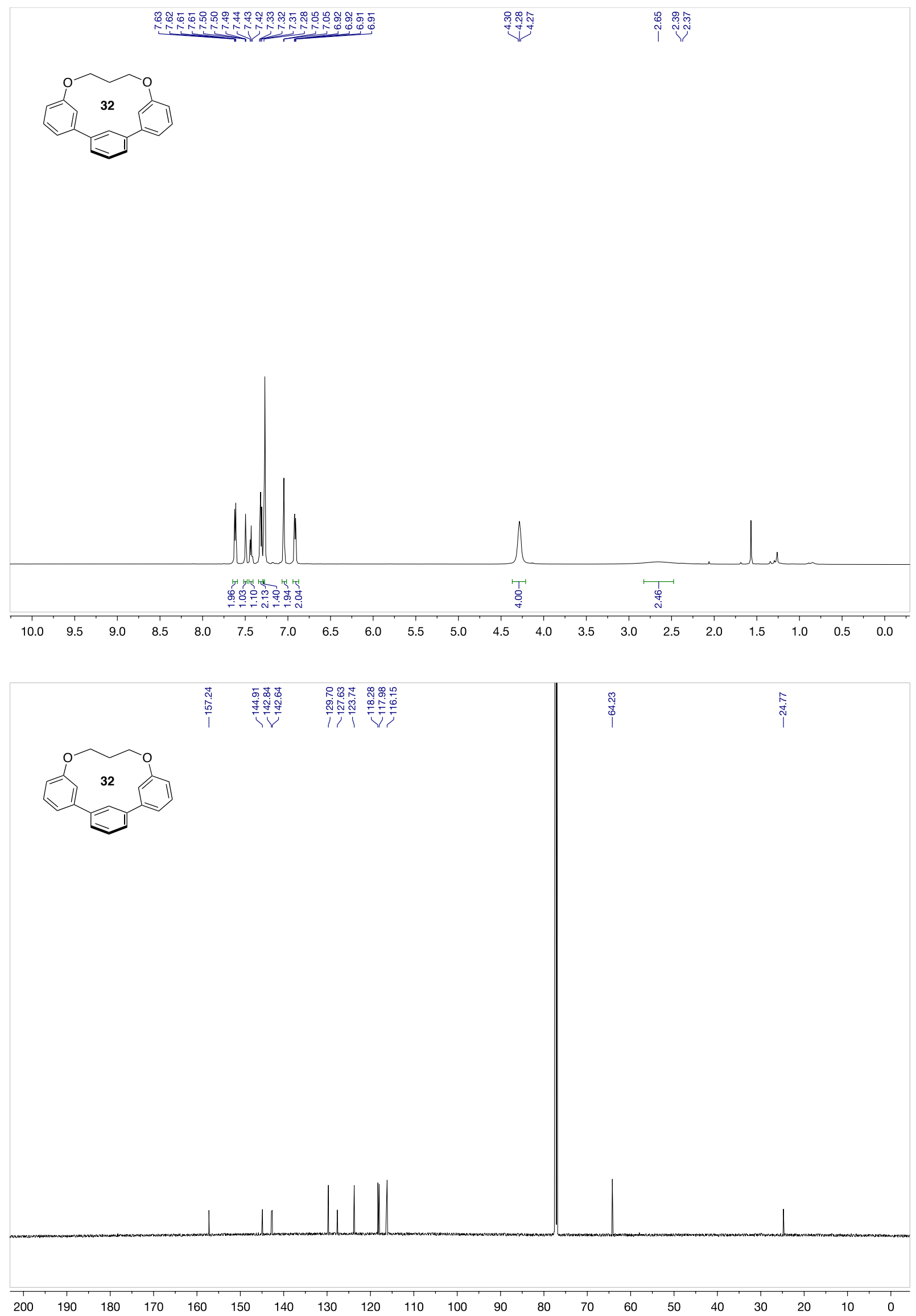

SI-30 


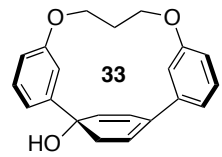

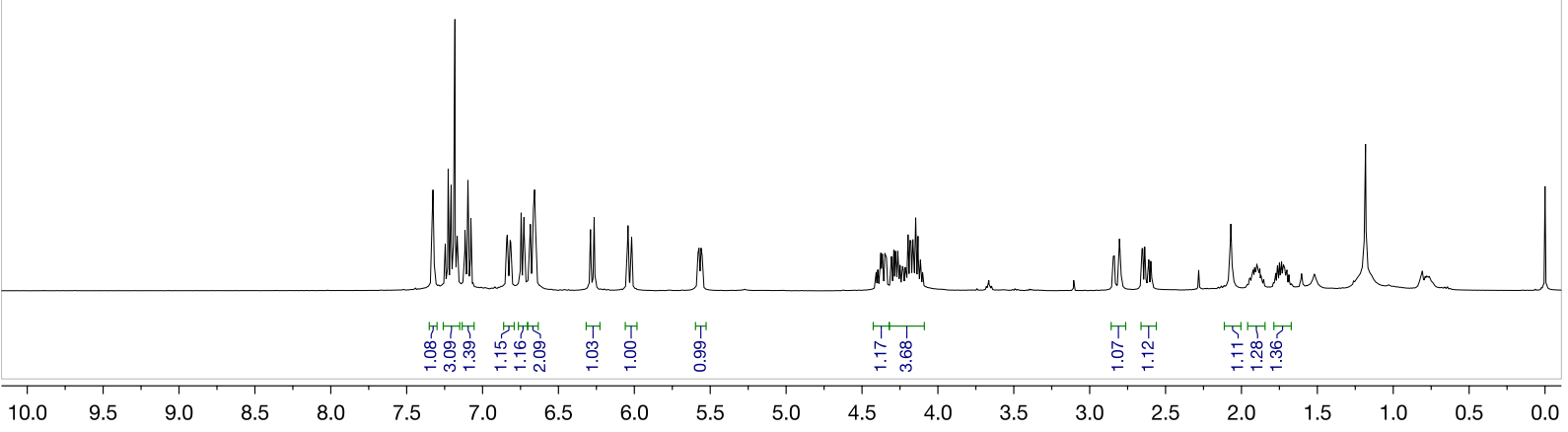

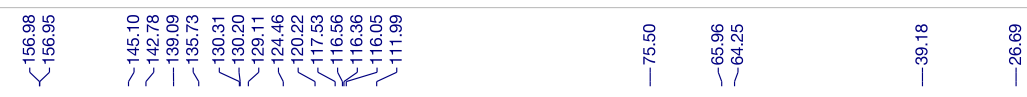
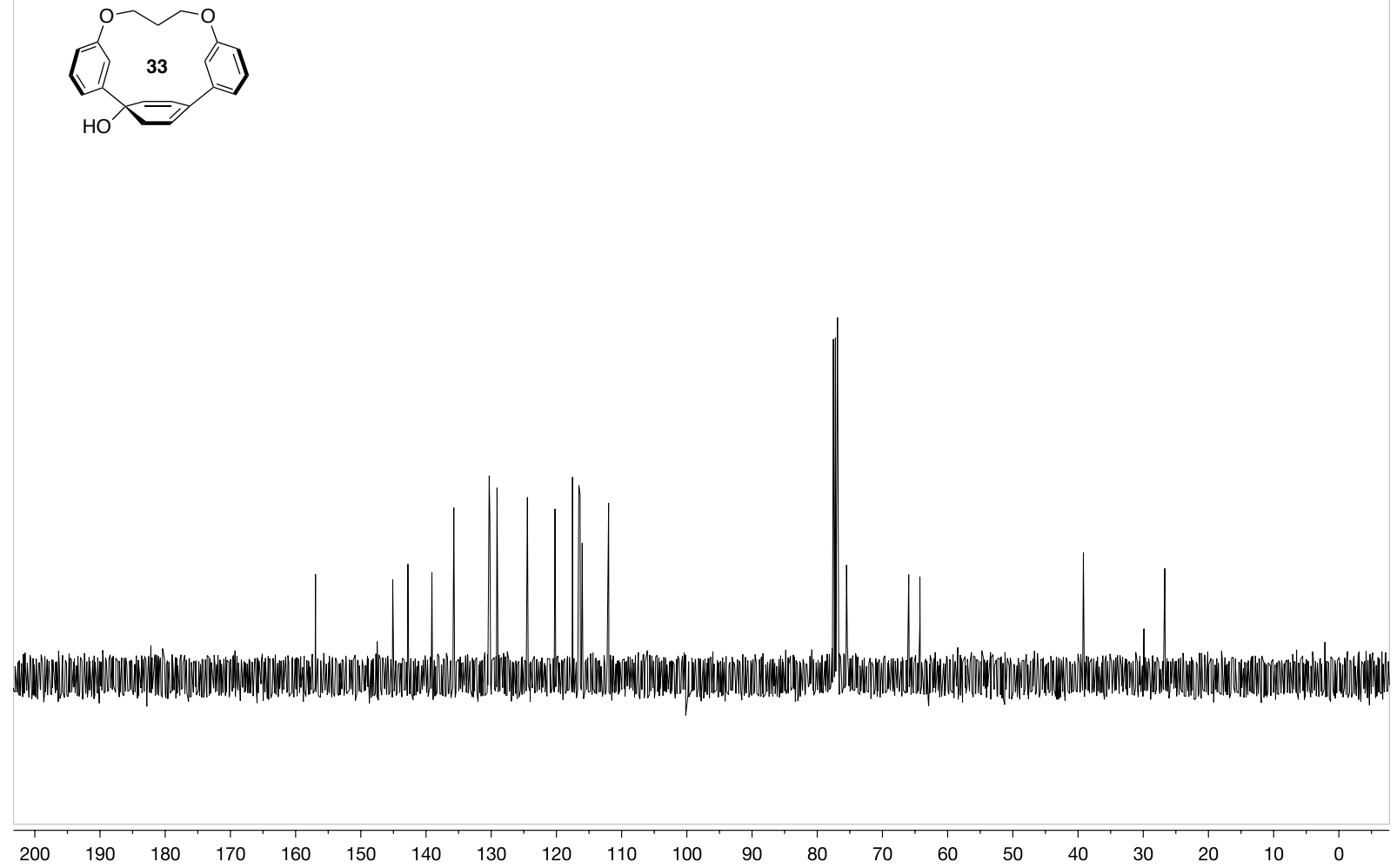

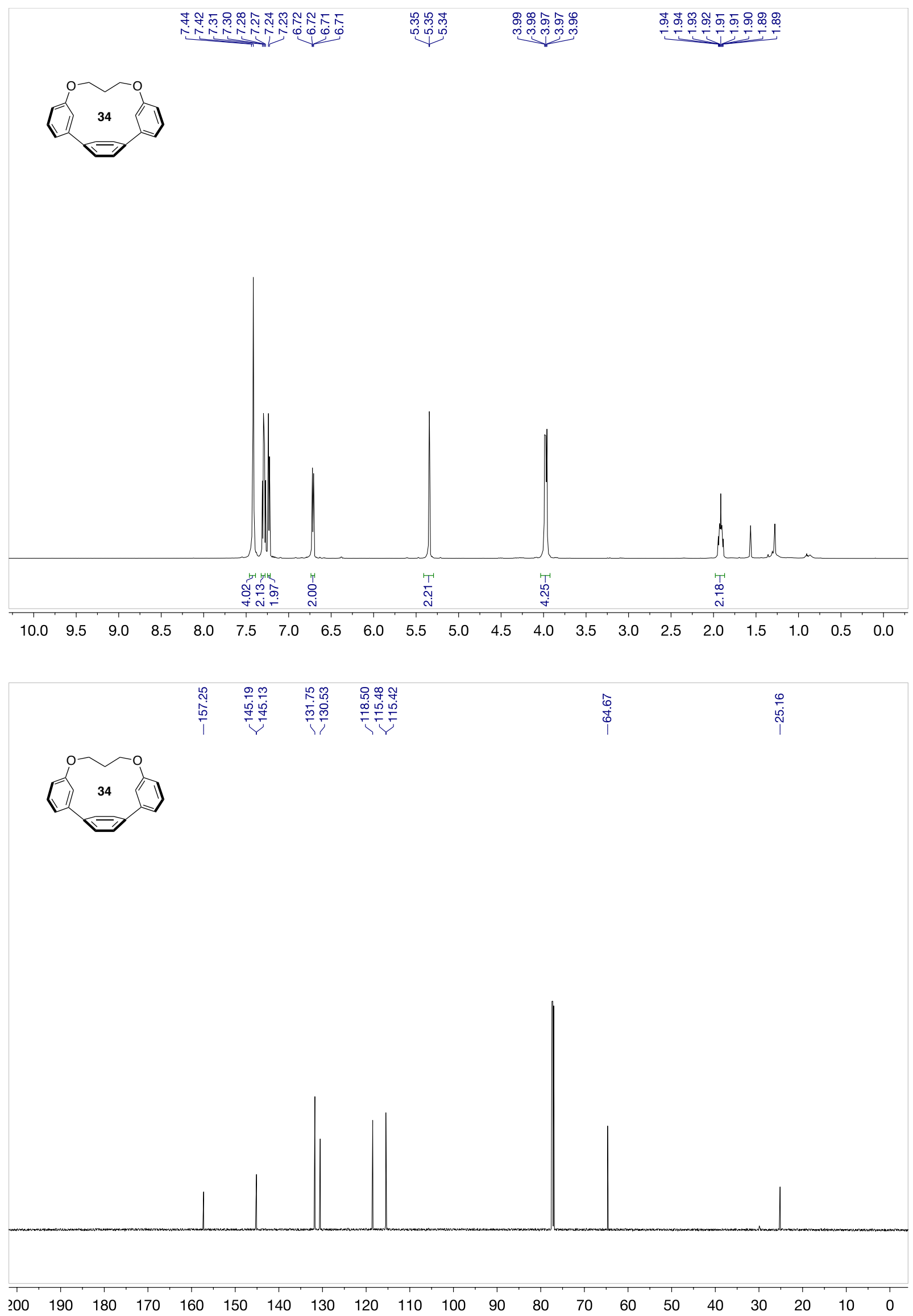

SI-32 


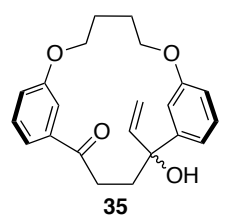

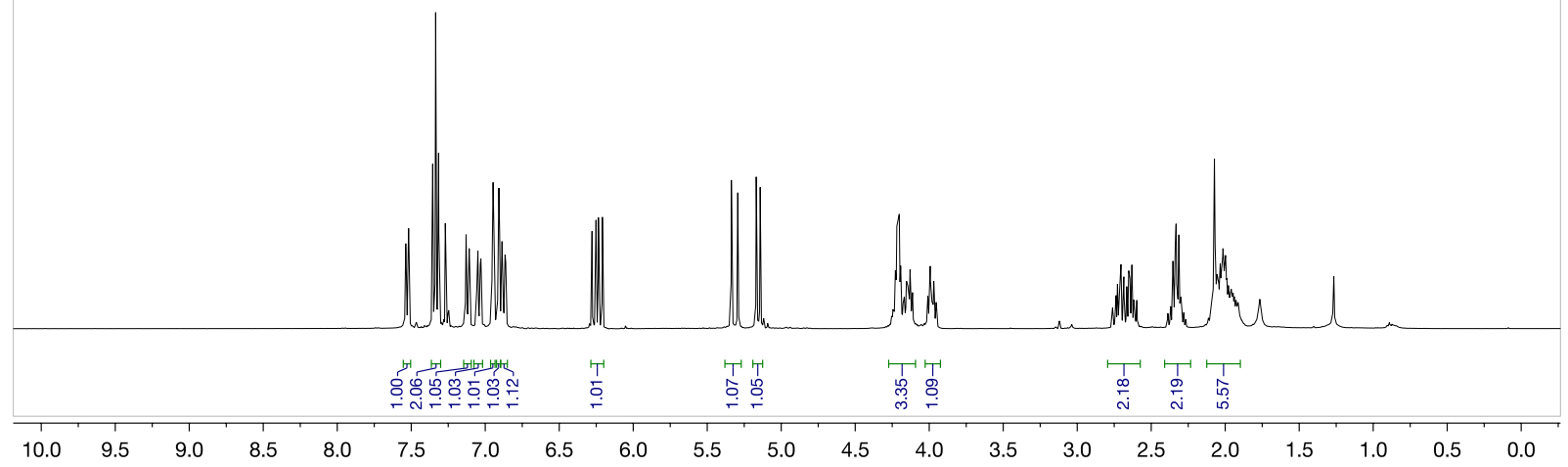

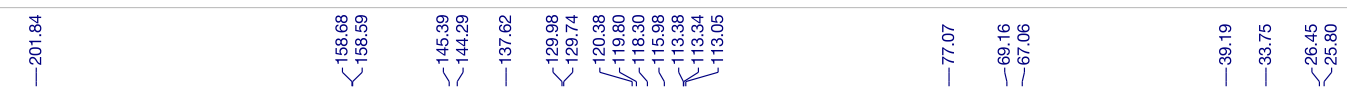<smiles>C=CC1(O)CCC2CCC(CC2)OCCCCOc2ccccc2O1</smiles>

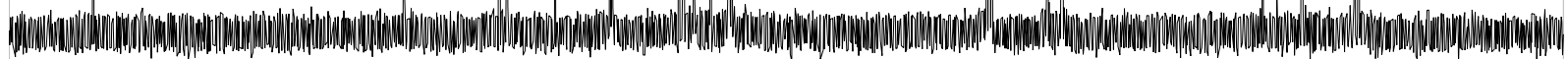

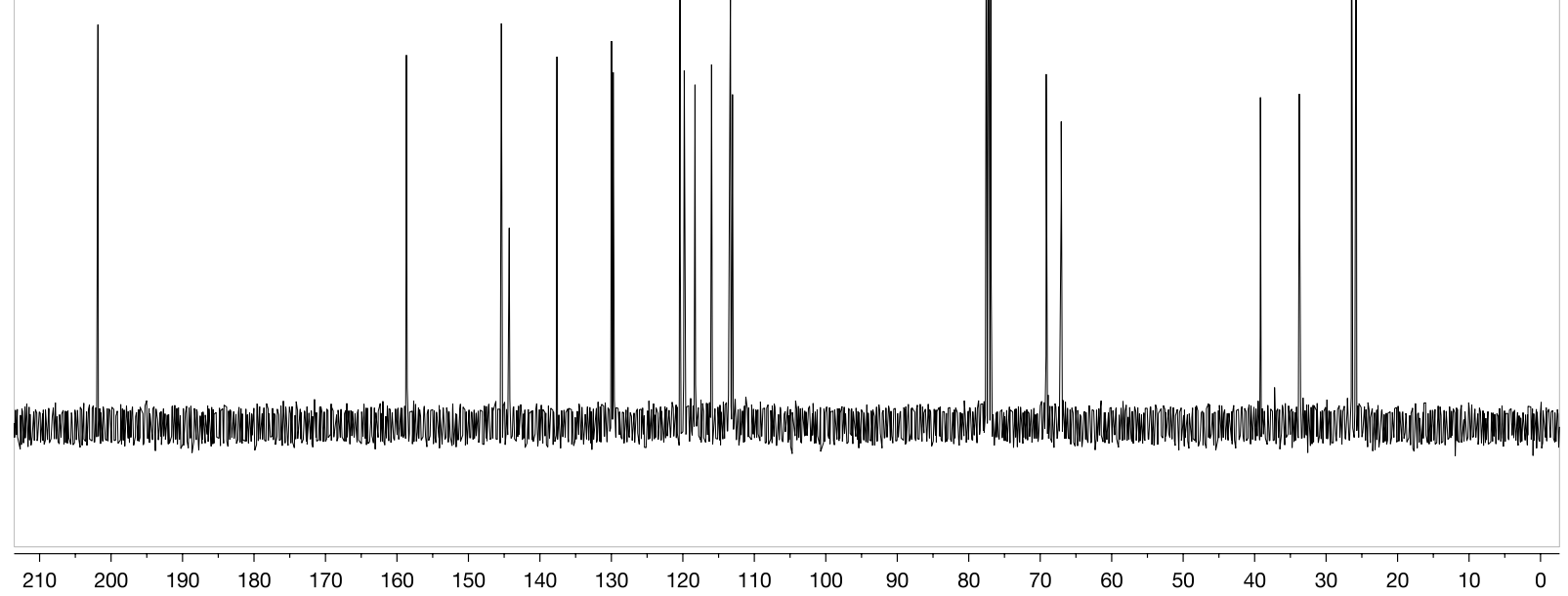


<smiles>C=CC(O)(CCCCCCCCOc1cccc(OCCCCCCCC)c1)c1ccccc1</smiles>

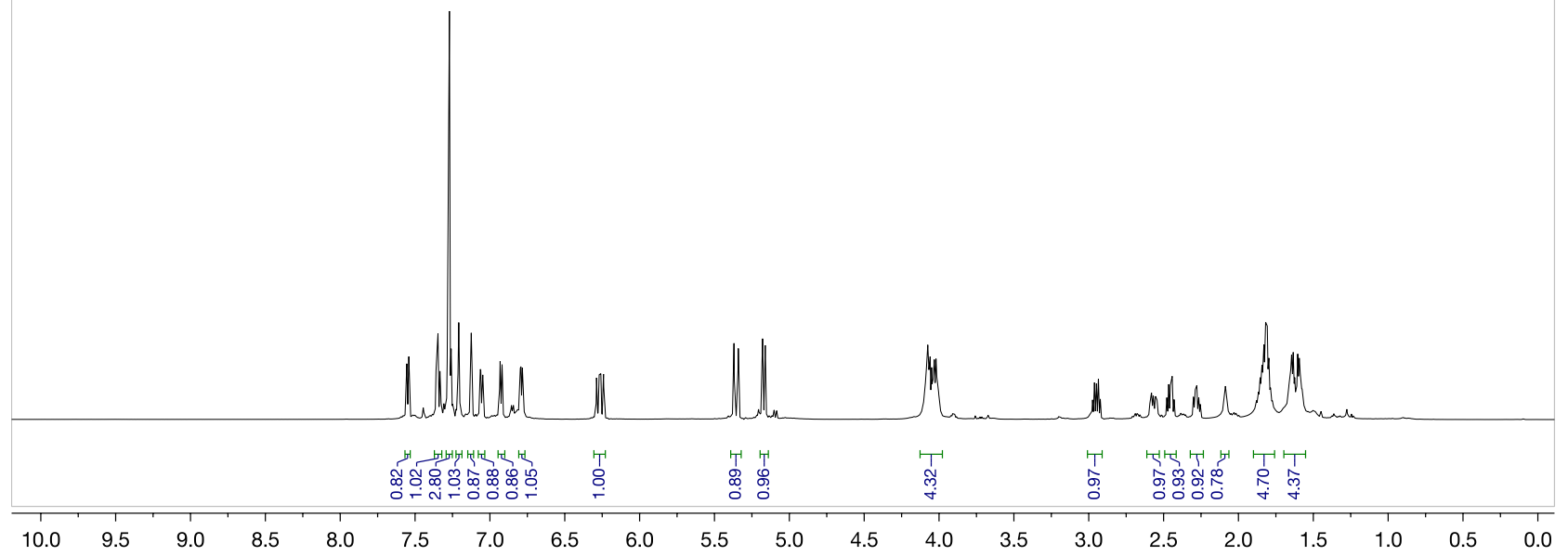

\begin{tabular}{|c|c|c|c|c|c|c|}
\hline 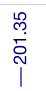 & 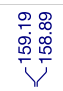 &  & 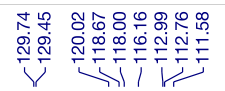 & $\underset{\substack{0 \\
\dot{e}}}{i}$ & 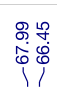 & 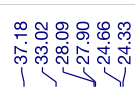 \\
\hline
\end{tabular}
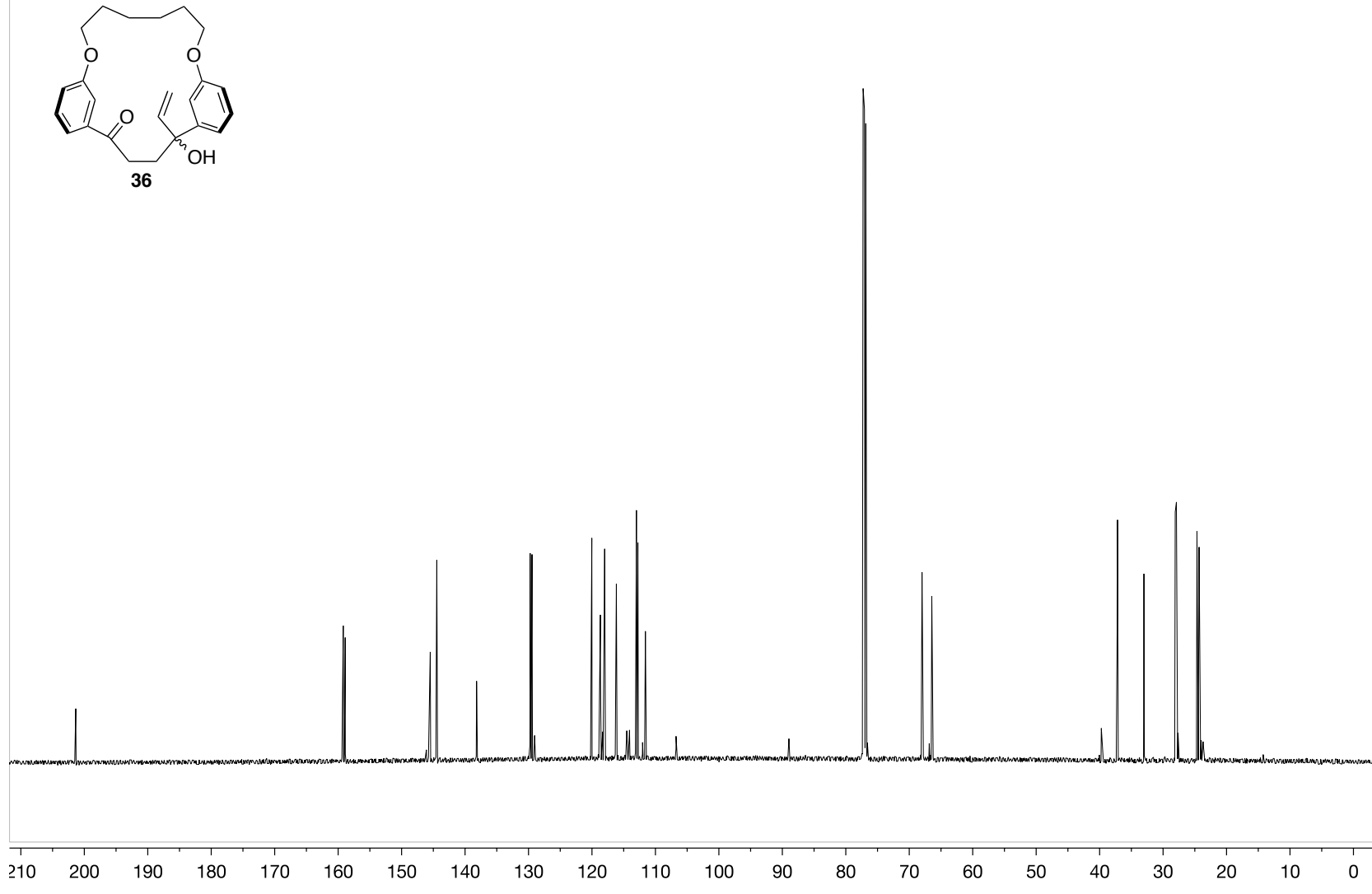


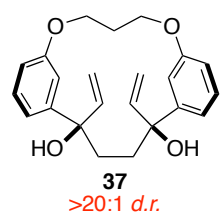
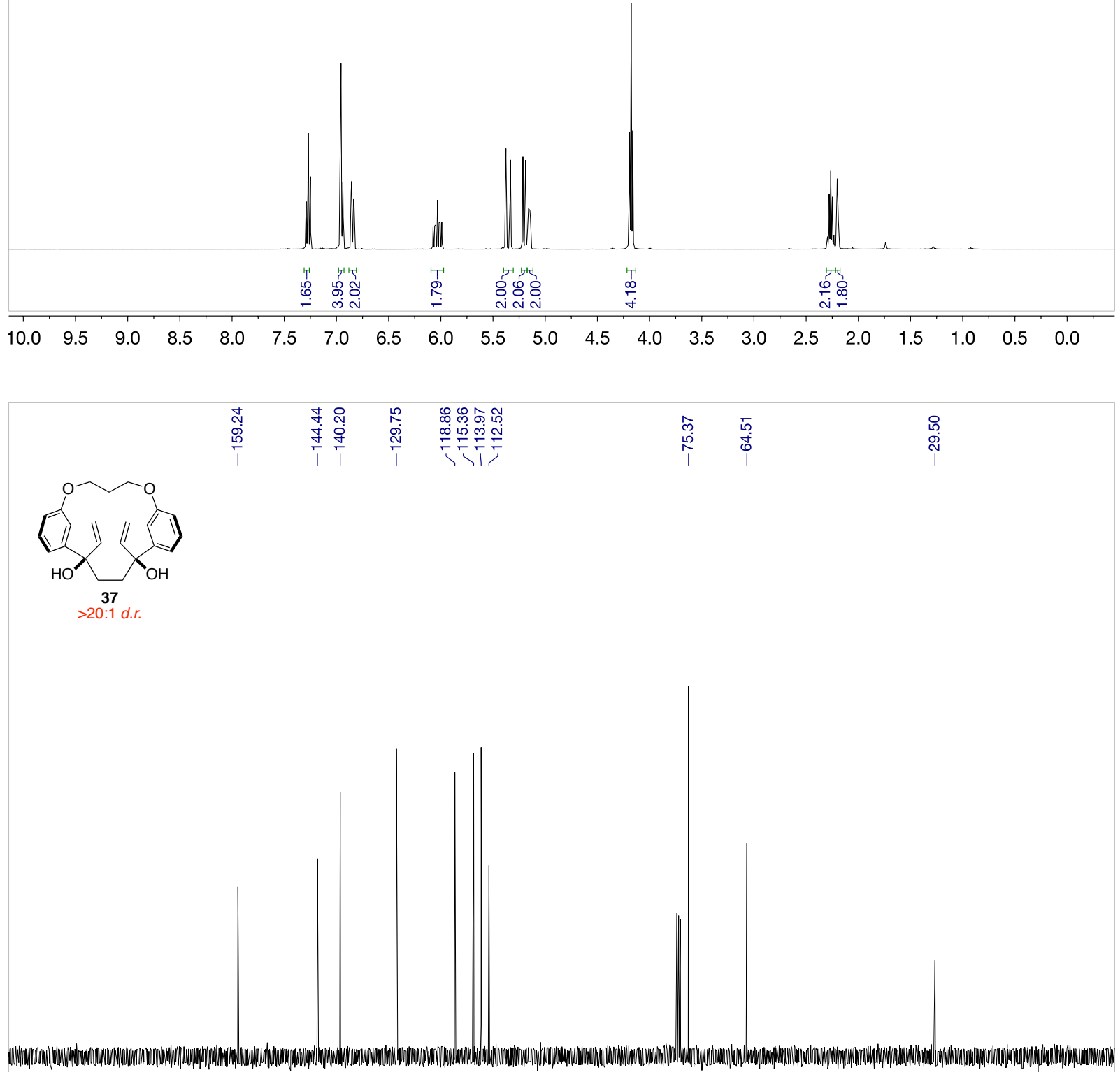

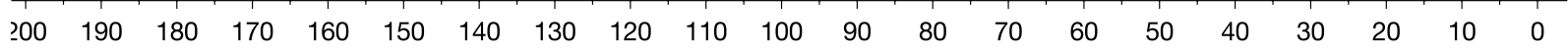




\section{X-ray Crystal Structure and Relevant Data for Compound 34}

Table SI-1: Crystal Data and Structure Refinement for (Merner060815) Compound 34

\begin{tabular}{|c|c|c|}
\hline Identification code & \multicolumn{2}{|l|}{ Merner060815 } \\
\hline Empirical formula & \multicolumn{2}{|l|}{$\mathrm{C}_{21} \mathrm{H}_{18} \mathrm{O}_{2}$} \\
\hline Formula weight & \multicolumn{2}{|l|}{304.37} \\
\hline Temperature & \multicolumn{2}{|l|}{$180(2) \mathrm{K}$} \\
\hline Wavelength & \multicolumn{2}{|l|}{$0.71073 \AA$} \\
\hline Crystal system & \multicolumn{2}{|l|}{ Orthorhombic } \\
\hline Space group & \multicolumn{2}{|l|}{$\mathrm{Pbca}$} \\
\hline \multirow[t]{3}{*}{ Unit cell dimensions } & $\mathrm{a}=19.549(2) \AA$ & $\alpha=90^{\circ}$ \\
\hline & $\mathrm{b}=8.1172(8) \AA$ & $\beta=90^{\circ}$ \\
\hline & $c=19.927(2) \AA$ & $\gamma=90^{\circ}$ \\
\hline Volume & \multicolumn{2}{|l|}{$3162.1(6) \AA^{3}$} \\
\hline Z & \multicolumn{2}{|l|}{8} \\
\hline Density (calculated) & \multicolumn{2}{|l|}{$1.279 \mathrm{~g} / \mathrm{cm}^{3}$} \\
\hline Absorption coefficient & \multicolumn{2}{|l|}{$0.081 \mathrm{~mm}^{-1}$} \\
\hline $\mathrm{F}(000)$ & \multicolumn{2}{|l|}{1296} \\
\hline Crystal size & \multicolumn{2}{|c|}{$0.17 \times 0.22 \times 0.25 \mathrm{~mm} 3$} \\
\hline Theta range for data collection & \multicolumn{2}{|l|}{2.04 to $28.35^{\circ}$} \\
\hline Index ranges & \multicolumn{2}{|c|}{$-25 \leq \mathrm{h} \leq 26,-10 \leq \mathrm{k} \leq 9,-26 \leq \mathrm{l} \leq 25$} \\
\hline Reflections collected & \multicolumn{2}{|l|}{31449} \\
\hline Independent reflections & \multicolumn{2}{|c|}{$3941[\mathrm{R}(\mathrm{int})=0.0561]$} \\
\hline Completeness to theta $=28.35^{\circ}$ & \multicolumn{2}{|l|}{$99.7 \%$} \\
\hline Absorption correction & \multicolumn{2}{|l|}{ Multiscan } \\
\hline Max. and min. transmission & \multicolumn{2}{|c|}{0.9860 and 0.9800} \\
\hline Refinement method & \multicolumn{2}{|c|}{ Full-matrix least-squares on F2 } \\
\hline Data / restraints / parameters & \multicolumn{2}{|l|}{$3941 / 0$ / 220} \\
\hline Goodness-of-fit on F2 & \multicolumn{2}{|l|}{1.212} \\
\hline Final $\mathrm{R}$ indices [I>2sigma(I)] & \multicolumn{2}{|c|}{$\mathrm{R} 1=0.0602, \mathrm{wR} 2=0.1070$} \\
\hline $\mathrm{R}$ indices (all data) & \multicolumn{2}{|c|}{$\mathrm{R} 1=0.0725, \mathrm{wR} 2=0.1120$} \\
\hline Largest diff. peak and hole & \multicolumn{2}{|l|}{0.245 and -0.196} \\
\hline
\end{tabular}

Table SI-2: Bond Lengths and Angles for (Merner060815) Compound 34

$\begin{array}{ll}\text { O1-C26 } & 1.378(2) \\ \text { O1-C2 } & 1.442(2) \\ \text { O8-C21 } & 1.380(2) \\ \text { O8-C4 } & 1.446(2) \\ \text { C9-C10 } & 1.385(3) \\ \text { C9-C21 } & 1.393(2) \\ \text { C21-C20 } & 1.381(2) \\ \text { C20-C22 } & 1.404(2) \\ \text { C22-C11 } & 1.381(2)\end{array}$




$\begin{array}{ll}\text { C22-C23 } & 1.502(2) \\ \text { C23-C12 } & 1.399(2) \\ \text { C23-C19 } & 1.401(2) \\ \text { C19-C18 } & 1.385(2) \\ \text { C18-C24 } & 1.402(2) \\ \text { C24-C13 } & 1.397(2) \\ \text { C24-C25 } & 1.493(2) \\ \text { C25-C14 } & 1.388(2) \\ \text { C25-C17 } & 1.408(2) \\ \text { C14-C15 } & 1.389(3) \\ \text { C15-C16 } & 1.382(3) \\ \text { C16-C26 } & 1.396(2) \\ \text { C26-C17 } & 1.381(2) \\ \text { C2-C3 } & 1.532(2) \\ \text { C3-C4 } & 1.528(2) \\ \text { C13-C12 } & 1.393(2) \\ \text { C11-C10 } & 1.397(3)\end{array}$

C26-O1-C2

C21-O8-C4

C10-C9-C21

O8-C21-C20

O8-C21-C9

C20-C21-C9

C21-C20-C22

C11-C22-C20

C11-C22-C23

C20-C22-C23

C12-C23-C19

C12-C23-C22

C19-C23-C22

C18-C19-C23

C19-C18-C24

C13-C24-C18

C13-C24-C25

C18-C24-C25

C14-C25-C17

C14-C25-C24

C17-C25-C24

C25-C14-C15

C16-C15-C14

C15-C16-C26

O1-C26-C17

O1-C26-C16

C17-C26-C16

O1-C2-C3
118.22(13)

117.43(13)

119.00(16)

122.78(15)

118.17(15)

119.04(16)

122.07(16)

118.72(16)

131.59(16)

109.46(14)

117.73(16)

117.76(15)

117.27(15)

120.23(16)

119.54(16)

117.81(17)

118.04(15)

118.95(16)

118.71(17)

128.43(17)

111.69(15)

119.29(18)

121.99(17)

119.10(17)

123.68(16)

117.00(16)

119.28(17)

114.53(15) 


$\begin{array}{ll}\text { C4-C3-C2 } & 108.95(14) \\ \text { O8-C4-C3 } & 115.00(14) \\ \text { C26-C17-C25 } & 121.48(16) \\ \text { C12-C13-C24 } & 120.11(16) \\ \text { C13-C12-C23 } & 119.46(16) \\ \text { C22-C11-C10 } & 119.08(17) \\ \text { C9-C10-C11 } & 122.05(17)\end{array}$

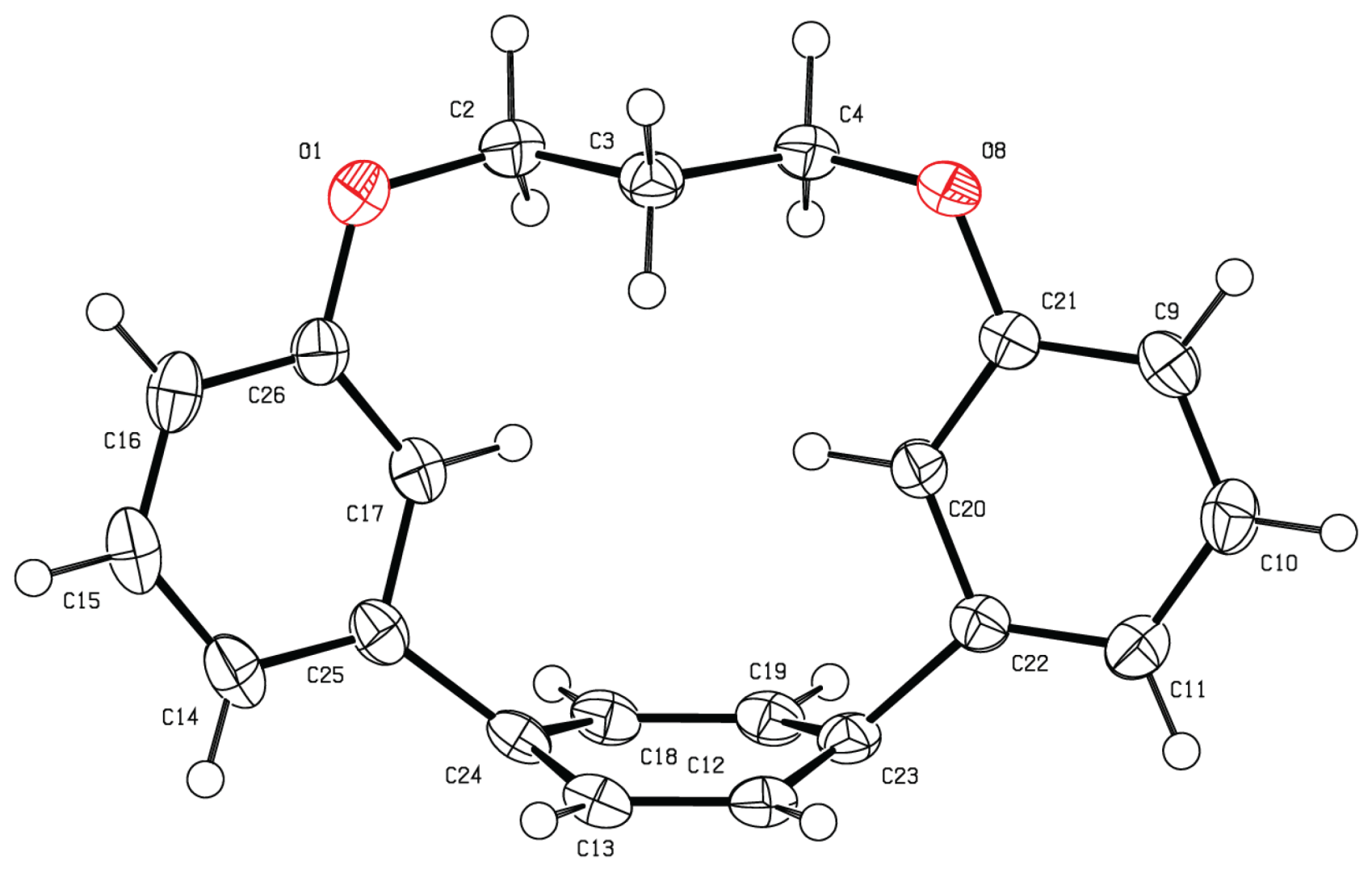

FIGURE SI-2: X-ray crystal structure of compound 34

Table SI-1: Crystal Data and Structure Refinement for (Merner121114) Compound 28

Identification code

Empirical formula

Formula weight

Temperature

Crystal system

Space group

Unit cell dimensions
Merner121114

$\mathrm{C}_{22} \mathrm{H}_{20} \mathrm{O}_{2}$

316.40

$180.45 \mathrm{~K}$

Monoclinic

$\mathrm{P} 21 / \mathrm{n}$

$\mathrm{a}=12.5333(3) \AA \quad \alpha=90^{\circ}$ 
Volume

Z

Density (calculated)

Absorption coefficient

$\mathrm{F}(000)$

Crystal size

Theta range for data collection

Index ranges

Reflections collected

Independent reflections

Data / restraints / parameters

Goodness-of-fit on F2

Final $R$ indices [I $>2 \operatorname{sigma}(\mathrm{I})$ ]

$\mathrm{R}$ indices (all data)

Largest diff. peak and hole $\mathrm{b}=7.8729(2) \AA$

$\mathrm{c}=16.2274(4) \AA$

$1600.48(7) \AA^{3}$

4

$1.3130 \mathrm{~g} / \mathrm{cm}^{3}$

$0.083 \mathrm{~mm}^{-1}$

672.3

$0.5 \times 0.4 \times 0.2 \mathrm{~mm}^{3}$

4.04 to $74.34^{\circ}$

$-21 \leq \mathrm{h} \leq 20,-13 \leq \mathrm{k} \leq 13,-27 \leq 1 \leq 27$

47977

$8058[\mathrm{R}(\mathrm{int})=0.0586, \mathrm{R}($ sigma $)=0.0452]$

8058 / 0 / 217

1.099

$\mathrm{R} 1=0.0682, \mathrm{wR} 2=0.1560$

$\mathrm{R} 1=0.0984, \mathrm{wR} 2=0.1826$

0.70 and -0.47

Table SI-3: Bond Lengths and Angles for (Merner121114) Compound 28

$\begin{array}{ll}\text { O1-C0aa } & 1.371(2) \\ \text { O1-C2 } & 1.449(2) \\ \text { O8-C5 } & 1.446(2) \\ \text { O8-C7 } & 1.374(2) \\ \text { C15-C0aa } & 1.402(2) \\ \text { C15-C14 } & 1.389(2) \\ \text { C16-C0aa } & 1.389(2) \\ \text { C2-C3 } & 1.536(2) \\ \text { C3-C4 } & 1.536(2) \\ \text { C4-C5 } & 1.532(2) \\ \text { C7-C9 } & 1.400(2) \\ \text { C7-C20 } & 1.391(2) \\ \text { C9-C10 } & 1.388(2) \\ \text { C14-C13 } & 1.397(2) \\ \text { C13-C3aa } & 1.400(2) \\ \text { C16-C3aa } & 1.406(2) \\ \text { C3aa-C4aa } & 1.488(2) \\ \text { C20-C1aa } & 1.405(2) \\ \text { C1aa-C5aa } & 1.490(2) \\ \text { C1aa-C11 } & 1.395(2) \\ \text { C5aa-C19 } & 1.401(2) \\ \text { C12-C4aa } & 1.399(2) \\ \text { C4aa-C17 } & 1.402(2) \\ \text { C17-C18 } & 1.398(2)\end{array}$




$\begin{array}{ll}\text { C18-C19 } 1.394(2) \\ \text { C11-C10 } & \\ & \\ \text { C2-O1-C0aa } & 116.75(9) \\ \text { C7-O8-C5 } & 117.99(9) \\ \text { C14-C15-C0aa } & 118.66(11) \\ \text { C15-C0aa-O1 } & 117.83(10) \\ \text { C16-C0aa-O1 } & 122.70(11) \\ \text { C16-C0aa-C15 } & 119.45(12) \\ \text { C2-C3-O1 } & 114.34(10) \\ \text { C4-C3-C2 } & 111.52(10) \\ \text { C5-C4-C3 } & 112.70(11) \\ \text { C4-C5-O8 } & 112.90(11) \\ \text { C9-C7-O8 } & 117.14(11) \\ \text { C20-C7-O8 } & 123.94(11) \\ \text { C20-C7-C9 } & 118.91(12) \\ \text { C10-C9-C7 } & 119.77(11) \\ \text { C13-C14-C15 } & 121.99(11) \\ \text { C13-C24-C18 } & 119.73(10) \\ \text { C3aa-C13-C14 } & 117.93(10) \\ \text { C4aa-C3aa-C13 } & 124.74(11) \\ \text { C4aa-C3aa-C16 } & 117.09(9) \\ \text { C3aa-C16-C0aa } & 122.18(11) \\ \text { C1aa-C20-C7 } & 121.30(11) \\ \text { C5aa-C1aa-C20 } & 115.27(18) \\ \text { C11-C1aa-C20 } & 119.47(11) \\ \text { C11-C1aa-C5aa } & 125.09(11) \\ \text { C12-C5aa-C1aa } & 115.29(10) \\ \text { C19-C5aa-C12 } & 118.34(10) \\ \text { C4aa-C12-C5aa } & 123.12(10) \\ \text { C12-C4aa-C3aa } & 118.00(10) \\ \text { C17-C4aa-C3aa } & 124.22(10) \\ \text { C17-C4aa-C12 } & 117.21(10) \\ \text { C18-C17-C4aa } & 120.09(10) \\ \text { C19-C18-C17 } & 121.52(11) \\ \text { C18-C19-C5aa } & 119.18(12) \\ \text { C10-C11-C1aa } & 118.89(12) \\ \text { C11-C10-C9 } & 121.55(12) \\ & \end{array}$




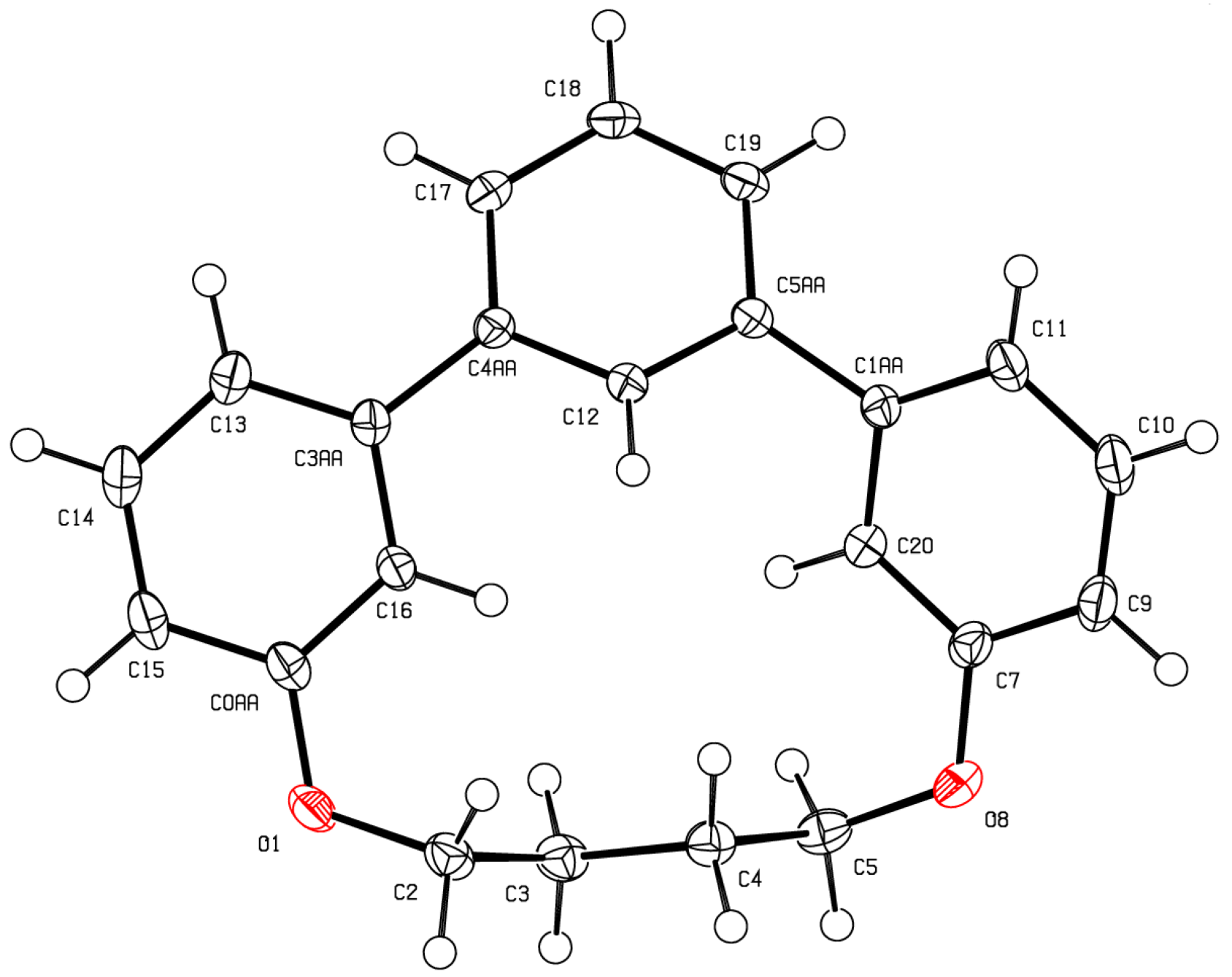

FIGURE SI-3: X-ray crystal structure of compound 28 


\section{DFT Computed Strain Energies of 31 and 34}

Full geometry optimization using the geometry from the CIF of $\mathbf{3 4}$ as a starting guess was performed using the B3LYP functional in conjunction with a 6-31G(d) basis set. The harmonic vibrational analysis was done at the same level to verify the nature of the stationary point. All of the electronic calculations were performed with Gaussian $09^{1}$ package of programs.

Cartesian Coordinates for 31 (in $\AA$ ):

$\begin{array}{lrrr}\mathrm{C} & 0.3212660 & 2.7493050 & -0.0453390 \\ \mathrm{H} & 0.5628480 & 2.2260540 & -0.9830630 \\ \mathrm{H} & 0.3868140 & 2.0230740 & 0.7656570 \\ \mathrm{C} & 1.3645940 & 3.8134910 & 0.2380560 \\ \mathrm{H} & 1.1964530 & 4.2491770 & 1.2294520 \\ \mathrm{H} & 1.3286080 & 4.6288670 & -0.4951910 \\ \mathrm{C} & 2.7511280 & 3.1445680 & 0.1691690 \\ \mathrm{H} & 3.0038250 & 2.9129420 & -0.8720530 \\ \mathrm{H} & 3.5222540 & 3.8097520 & 0.5701870 \\ \mathrm{C} & 3.7852380 & 0.4135700 & -0.6593360 \\ \mathrm{H} & 4.5455890 & 1.1438780 & -0.9195320 \\ \mathrm{C} & 3.7792020 & -0.8501160 & -1.2566500 \\ \mathrm{H} & 4.5414470 & -1.0945860 & -1.9918820 \\ \mathrm{C} & 2.8174130 & -1.7988090 & -0.9178490 \\ \mathrm{H} & 2.8345970 & -2.7801400 & -1.3814740 \\ \mathrm{C} & -0.1690700 & -2.1574780 & 1.4915120 \\ \mathrm{H} & 0.2253650 & -2.2545950 & 2.5032360 \\ \mathrm{C} & -1.4251280 & -1.7360260 & 1.3102530 \\ \mathrm{H} & -2.0536680 & -1.5014170 & 2.1674850 \\ \mathrm{C} & -3.9485900 & 0.2517810 & -0.1915970 \\ \mathrm{H} & -4.7181960 & -0.5108470 & -0.1931570 \\ \mathrm{C} & -4.2848820 & 1.6134600 & -0.2351330 \\ \mathrm{H} & -5.3325700 & 1.9006140 & -0.2777970 \\ \mathrm{C} & -3.3129450 & 2.6108900 & -0.2156330 \\ \mathrm{H} & -3.5787150 & 3.6632990 & -0.2369020 \\ \mathrm{C} & -1.6270970 & 0.8893910 & -0.1399920 \\ \mathrm{H} & -0.5952630 & 0.5799690 & -0.1027110 \\ \mathrm{C} & -1.1311970 & -1.8995930 & -1.2039300 \\ \mathrm{H} & -1.7444830 & -2.2248080 & -2.0509350 \\ \mathrm{H} & -0.6049580 & -0.9975070 & -1.5289930 \\ \mathrm{C} & -0.0924760 & -2.9678500 & -0.8463340 \\ \mathrm{H} & 0.5507580 & -3.1710620 & -1.7085080 \\ \mathrm{H} & -0.5764160 & -3.9168520 & -0.5826090 \\ & 1.8593210 & -0.2450900 & 0.6552210 \\ & 1.1293830 & 0.0083000 & 1.4160000\end{array}$




$\begin{array}{lrrr}\mathrm{C} & 2.8157150 & 0.7193440 & 0.2987620 \\ \mathrm{C} & 1.8291710 & -1.4997650 & 0.0352870 \\ \mathrm{C} & 0.7682730 & -2.5695350 & 0.3712640 \\ \mathrm{C} & -2.1041710 & -1.5566990 & -0.0393240 \\ \mathrm{C} & -2.6038140 & -0.1112260 & -0.1455760 \\ \mathrm{C} & -1.9610920 & 2.2440040 & -0.1595640 \\ \mathrm{H} & 2.1206790 & -3.5544940 & 1.4020730 \\ \mathrm{H} & -2.9602900 & -3.3030080 & 0.1494380 \\ \mathrm{O} & -1.0143240 & 3.2407660 & -0.1153490 \\ \mathrm{O} & 2.7833510 & 1.9332760 & 0.9542970 \\ \mathrm{O} & 1.4453800 & -3.7878210 & 0.7441140 \\ \mathrm{O} & -3.2605580 & -2.4090100 & -0.0778510\end{array}$

Cartesian Coordinates for $p$-terphenyl precursor of 31 (in $\AA$ ):

$\begin{array}{lrrr}\mathrm{C} & 4.0938360 & 2.3203580 & -0.2895740 \\ \mathrm{H} & 4.7114240 & 3.2018340 & -0.4396960 \\ \mathrm{C} & 4.5106410 & 1.0780030 & -0.7740900 \\ \mathrm{H} & 5.4558050 & 0.9888220 & -1.3035800 \\ \mathrm{C} & 3.7188600 & -0.0524580 & -0.5795430 \\ \mathrm{H} & 4.0467160 & -1.0191730 & -0.9499840 \\ \mathrm{C} & 0.6683050 & -1.1281390 & 1.4258760 \\ \mathrm{H} & 1.1189150 & -1.1549740 & 2.4186910 \\ \mathrm{C} & -0.6604510 & -1.0390050 & 1.3071900 \\ \mathrm{H} & -1.2902580 & -1.0232530 & 2.1946540 \\ \mathrm{C} & -3.8375350 & -0.3927280 & -0.3698930 \\ \mathrm{H} & -4.0494110 & -1.4293470 & -0.6026870 \\ \mathrm{C} & -4.8585410 & 0.5601300 & -0.3966920 \\ \mathrm{H} & -5.8686490 & 0.2547650 & -0.6580880 \\ \mathrm{C} & -4.5901970 & 1.8936820 & -0.0886440 \\ \mathrm{H} & -5.3868130 & 2.6327770 & -0.1082950 \\ \mathrm{C} & -2.2693220 & 1.3203550 & 0.2726540 \\ \mathrm{H} & -1.2600750 & 1.6259920 & 0.5374600 \\ \mathrm{C} & -0.4042270 & -0.7750700 & -1.1812630 \\ \mathrm{H} & -0.9096890 & -1.0207090 & -2.1210590 \\ \mathrm{H} & -0.1622310 & 0.2935320 & -1.2142040 \\ \mathrm{C} & 0.8848070 & -1.5867140 & -1.0292740 \\ \mathrm{H} & 1.5430460 & -1.4391260 & -1.8913950 \\ \mathrm{H} & 0.6590090 & -2.6600150 & -0.9868440 \\ \mathrm{C} & 2.0886720 & 1.2851140 & 0.5864590 \\ \mathrm{H} & 1.1535990 & 1.3710860 & 1.1316950 \\ \mathrm{C} & 2.8811930 & 2.4192950 & 0.3914310 \\ \mathrm{C} & 2.4937190 & 0.0361220 & 0.1005730 \\ \mathrm{C} & 1.6435830 & -1.2336100 & 0.2670970 \\ \mathrm{C} & -1.3942800 & -1.0447570 & -0.0228810\end{array}$




$\begin{array}{lrrr}\mathrm{C} & -2.5301470 & -0.0221220 & -0.0364780 \\ \mathrm{C} & -3.2885870 & 2.2712480 & 0.2476700 \\ \mathrm{H} & 3.1189280 & -2.1203240 & 1.2147190 \\ \mathrm{H} & -1.3170260 & -2.9992820 & 0.0087150 \\ \mathrm{O} & 2.5089670 & -2.3643380 & 0.4987390 \\ \mathrm{O} & -2.0025680 & -2.3414970 & -0.1843790 \\ \mathrm{H} & -3.0657640 & 3.3065400 & 0.4930230 \\ \mathrm{H} & 2.5493010 & 3.3793090 & 0.7782900\end{array}$

Cartesian Coordinates for alkoxy bridging group of 31 (in $\AA$ ):

$\begin{array}{lrrr}\mathrm{C} & 1.0016090 & -0.3573120 & 0.2886430 \\ \mathrm{H} & 0.9827770 & -0.3976060 & 1.3921430 \\ \mathrm{H} & 0.6823180 & -1.3458830 & -0.0834540 \\ \mathrm{C} & 0.0375080 & 0.7147830 & -0.2039330 \\ \mathrm{H} & 0.0637950 & 0.7379960 & -1.2995760 \\ \mathrm{H} & 0.3934530 & 1.6905240 & 0.1524140 \\ \mathrm{C} & -1.4046250 & 0.5057520 & 0.2635150 \\ \mathrm{H} & -1.4508640 & 0.4962440 & 1.3656130 \\ \mathrm{H} & -2.0223160 & 1.3428360 & -0.0760810 \\ \mathrm{O} & 2.3002940 & -0.0319070 & -0.1910680 \\ \mathrm{O} & -2.0185440 & -0.6605370 & -0.2811930 \\ \mathrm{H} & 2.9093110 & -0.7292060 & 0.0952710 \\ \mathrm{H} & -1.6194180 & -1.4346830 & 0.1424080\end{array}$

Cartesian Coordinates for 34 (in $\AA$ ):

$\begin{array}{llll}\mathrm{O} & 2.5008600 & 2.4769540 & -0.0663690 \\ \mathrm{O} & -2.5014700 & 2.4767900 & -0.0661030 \\ \mathrm{C} & -4.1810510 & 0.9095340 & -0.6688080 \\ \mathrm{H} & -4.7964100 & 1.7394290 & -1.0019400 \\ \mathrm{C} & -2.9197620 & 1.1707590 & -0.1102330 \\ \mathrm{C} & -2.1481990 & 0.1000130 & 0.3274770 \\ \mathrm{H} & -1.1628060 & 0.2712500 & 0.7349810 \\ \mathrm{C} & -2.5507840 & -1.2384260 & 0.1382700 \\ \mathrm{C} & -1.4005580 & -2.1747890 & 0.3530230 \\ \mathrm{C} & -0.6964980 & -2.1262590 & 1.5686650 \\ \mathrm{C} & 0.6970860 & -2.1262570 & 1.5685580 \\ \mathrm{C} & 1.4009580 & -2.1748010 & 0.3528020 \\ \mathrm{C} & 2.5510250 & -1.2382610 & 0.1379540 \\ \mathrm{C} & 3.8009490 & -1.4923690 & -0.4263360 \\ \mathrm{H} & 4.1368800 & -2.5121720 & -0.5901390 \\ \mathrm{C} & 4.6098300 & -0.4092790 & -0.8028310 \\ \mathrm{H} & 5.5890240 & -0.6012880 & -1.2340140\end{array}$




$\begin{array}{lrrr}\mathrm{C} & 4.1810410 & 0.9101030 & -0.6686090 \\ \mathrm{H} & 4.7963420 & 1.7401210 & -1.0015280 \\ \mathrm{C} & 2.9194940 & 1.1710300 & -0.1104680 \\ \mathrm{C} & 1.2702900 & 2.8011090 & 0.5947750 \\ \mathrm{H} & 1.3708210 & 3.8625900 & 0.8413240 \\ \mathrm{H} & 1.2084350 & 2.2507010 & 1.5436210 \\ \mathrm{C} & -0.0003560 & 2.5756450 & -0.2525400 \\ \mathrm{H} & -0.0003810 & 3.2626500 & -1.1058070 \\ \mathrm{H} & -0.0004650 & 1.5632290 & -0.6645240 \\ \mathrm{C} & -1.2709150 & 2.8012130 & 0.5949060 \\ \mathrm{H} & -1.2089050 & 2.2510100 & 1.5438660 \\ \mathrm{H} & -1.3715240 & 3.8627310 & 0.8412410 \\ \mathrm{C} & 2.1480260 & 0.1000840 & 0.3268960 \\ \mathrm{H} & 1.1624350 & 0.2710810 & 0.7340060 \\ \mathrm{C} & 0.6983360 & -2.6030540 & -0.7856340 \\ \mathrm{C} & -0.6981190 & -2.6030650 & -0.7855200 \\ \mathrm{C} & -3.8004470 & -1.4928280 & -0.4265040 \\ \mathrm{H} & -4.1360110 & -2.5127210 & -0.5904740 \\ \mathrm{C} & -4.6094880 & -0.4099420 & -0.8032070 \\ \mathrm{H} & -5.5884960 & -0.6021560 & -1.2347140 \\ \mathrm{H} & -1.2284750 & -1.8857580 & 2.4860930 \\ \mathrm{H} & -1.2239940 & -2.7029460 & -1.7318650 \\ \mathrm{H} & 1.2240680 & -2.7029390 & -1.7320590 \\ \mathrm{H} & 1.2292030 & -1.8857230 & 2.48588\end{array}$

Cartesian Coordinates for alkoxy bridging group of 34 (in $\AA$ ):

$\begin{array}{lrrr}\mathrm{O} & 2.4612860 & -0.2841330 & -0.1052280 \\ \mathrm{O} & -2.4612860 & -0.2841330 & -0.1052270 \\ \mathrm{C} & 1.2781130 & 0.4911610 & 0.0459260 \\ \mathrm{H} & 1.3095390 & 1.2271150 & -0.7649240 \\ \mathrm{H} & 1.2914070 & 1.0549930 & 0.9941160 \\ \mathrm{C} & 0.0000000 & -0.3454170 & -0.0538550 \\ \mathrm{H} & 0.0000000 & -0.8947320 & -1.0022630 \\ \mathrm{H} & 0.0000000 & -1.0978860 & 0.7523190 \\ \mathrm{C} & -1.2781130 & 0.4911610 & 0.0459260 \\ \mathrm{H} & -1.2914070 & 1.0549940 & 0.9941150 \\ \mathrm{H} & -1.3095390 & 1.2271150 & -0.7649250 \\ \mathrm{H} & -2.4862720 & -0.9234540 & 0.6236060 \\ \mathrm{H} & 2.4862760 & -0.9234500 & 0.6236090\end{array}$

Cartesian Coordinates for $p$-terphenyl system of 34 (in $\AA$ ):

C $\quad-5.7300110 \quad 0.0001460 \quad-0.0001880$

$\mathrm{H} \quad-6.8166550 \quad 0.0001850 \quad-0.0001910$ 


$\begin{array}{lrrr}\mathrm{C} & -5.0259130 & 1.1822850 & -0.2365940 \\ \mathrm{C} & -3.6319500 & 1.1815670 & -0.2373110 \\ \mathrm{H} & -3.0949770 & 2.1018100 & -0.4500820 \\ \mathrm{C} & -2.9087790 & -0.0000600 & 0.0000040 \\ \mathrm{C} & -1.4246130 & -0.0001210 & 0.0001530 \\ \mathrm{C} & -0.6956500 & 1.0835930 & 0.5181180 \\ \mathrm{C} & 0.6956500 & 1.0835920 & 0.5181180 \\ \mathrm{C} & 1.4246130 & -0.0001210 & 0.0001530 \\ \mathrm{C} & 2.9087790 & -0.0000600 & 0.0000040 \\ \mathrm{C} & 3.6321460 & -1.1815610 & 0.2373210 \\ \mathrm{H} & 3.0953000 & -2.1018500 & 0.4502030 \\ \mathrm{C} & 5.0260970 & -1.1820670 & 0.2363700 \\ \mathrm{H} & 5.5633960 & -2.1068890 & 0.4299920 \\ \mathrm{C} & 5.7300110 & 0.0001460 & -0.0001880 \\ \mathrm{H} & 6.8166540 & 0.0001850 & -0.0001900 \\ \mathrm{C} & 5.0259120 & 1.1822860 & -0.2365910 \\ \mathrm{C} & 3.6319490 & 1.1815670 & -0.2373080 \\ \mathrm{H} & 3.0949760 & 2.1018110 & -0.4500760 \\ \mathrm{C} & 0.6956480 & -1.0838220 & -0.5178670 \\ \mathrm{C} & -0.6956470 & -1.0838220 & -0.5178660 \\ \mathrm{C} & -3.6321460 & -1.1815600 & 0.2373240 \\ \mathrm{H} & -3.0953000 & -2.1018490 & 0.4502080 \\ \mathrm{C} & -5.0260970 & -1.1820670 & 0.2363730 \\ \mathrm{H} & -5.5633950 & -2.1068890 & 0.4299970 \\ \mathrm{H} & -1.2267650 & 1.9225390 & 0.9592850 \\ \mathrm{H} & -1.2267790 & -1.9227620 & -0.9590250 \\ \mathrm{H} & 1.2267790 & -1.9227620 & -0.9590250 \\ \mathrm{H} & 1.2267660 & 1.9225380 & 0.9592850 \\ \mathrm{H} & -5.5630360 & 2.1071990 & -0.4302730 \\ & 5.5630350 & 2.1072000 & -0.4302670\end{array}$

[1.] Gaussian 09, Revision D.01: M. J. Frisch, G. W. Trucks, H. B. Schlegel, G. E. Scuseria, M. A. Robb, J. R. Cheeseman, G. Scalmani, V. Barone, B. Mennucci, G. A. Petersson, H. Nakatsuji, M. Caricato, X. Li, H. P. Hratchian, A. F. Izmaylov, J. Bloino, G. Zheng, J. L. Sonnenberg, M. Hada, M. Ehara, K. Toyota, R. Fukuda, J. Hasegawa, M. Ishida, T. Nakajima, Y. Honda, O. Kitao, H. Nakai, T. Vreven, J. A. Montgomery, Jr., J. E. Peralta, F. Ogliaro, M. Bearpark, J. J. Heyd, E. Brothers, K. N. Kudin, V. N. Staroverov, R. Kobayashi, J. Normand, K. Raghavachari, A. Rendell, J. C. Burant, S. S. Iyengar, J. Tomasi, M. Cossi, N. Rega, J. M. Millam, M. Klene, J. E. Knox, J. B. Cross, V. Bakken, C. Adamo, J. Jaramillo, R. Gomperts, R. E. Stratmann, O. Yazyev, A. J. Austin, R. Cammi, C. Pomelli, J. W. Ochterski, R. L. Martin, K. Morokuma, V. G. Zakrzewski, G. A. Voth, P. Salvador, J. J. Dannenberg, S. Dapprich, A. D. Daniels, Ö. Farkas, J. B. Foresman, J. V. Ortiz, J. Cioslowski, and D. J. Fox, Gaussian, Inc., Wallingford CT, 2009. 